\title{
Crystallization histories of the group IIF iron meteorites and Eagle Station pallasites
}

\author{
Connor D. Hilton, Richard D. Ash, and Richard J. Walker
}

Department of Geology, University of Maryland, College Park, Maryland, 20742, USA (chilton@terpmail.umd.edu)

\begin{abstract}
The group IIF iron meteorites and Eagle Station pallasites (PES) have highly siderophile element abundances (HSE; Re, Os, Ir, Ru, Pt, and Pd) of metal that are consistent with formation in planetesimal cores by fractional crystallization with minor to major solid metal-liquid metal mixing. Modeling of HSE abundances of the IIF irons indicates a complex formation history that included the mixing of primitive and evolved solid and liquid metals. By contrast, modeling of HSE abundances of PES metal suggests these meteorites formed mainly as equilibrium solids from a common liquid. Abundances of some of the siderophile elements in the IIF irons and PES are permissive of a common core origin, however, the abundances of $\mathrm{W}$ and $\mathrm{Ni}$ indicate the PES ultimately formed on a more oxidized body. The PES most likely formed by the injection of olivine present at the core-mantle boundary into a metallic core liquid as a result of impact. The core then crystallized inward, trapping the olivine.
\end{abstract}

\section{Introduction}

Some past studies have sought to explain the silicate and metal textures of pallasites by formation at the core-mantle boundary of planetesimals (Anders, 1964; Scott, 1977a; Wood, 1978). Other studies have called for pallasite origins by mixing of core metal and mantle materials 
through impact (Wasson and Choi, 2003; Yang et al., 2010), or mixing of mantle-derived metal and silicate above the core-mantle boundary (Urey, 1966; Mittlefehldt, 1980; Malvin et al., 1985; Davis and Olsen, 1991; Boesenberg et al., 2012). A key issue with most models of pallasite formation is the requirement for co-mingling silicate and liquid metal, which because of density differences, is difficult to achieve, even in low gravity environments. Nevertheless, density separation of tightly-packed liquid metal and silicates may have been prevented in some circumstances by the high pressure of overlying materials or rapid crystallization of the enclosing metal (Rayleigh, 1942; Scott, 1977b).

One potential key to discerning between different pallasite origin scenarios is to assess whether metal in pallasites formed in a manner similar to the planetesimal cores sampled by magmatic iron meteorites (Lovering et al., 1957). To do this, it is instructive to compare a pallasite or pallasite group to the most chemically similar magmatic iron meteorite group. Most attention relating to pallasite-iron comparisons has been focused on the possibility of a relation between the main group pallasites (PMG) and the group IIIAB iron meteorites (Scott, 1977a; Wasson and Choi, 2003). Due to the chemical similarities shared between these groups (Fig. 1), it has been argued that the PMG metal also formed in a planetesimal core (Yang et al., 2010), or even from the same parental melt to the IIIAB iron meteorites (Scott, 1977a; Wasson and Choi, 2003). In support of an origin on the same parent body, the PMG and IIIAB irons share similar "genetic" O, Mo, and S isotopic compositions (Clayton and Mayeda, 1996; Burkhardt et al., 2011; Dottin et al., 2018). However, differences in the measured cooling rates of PMG metal (2.5-18 K/Myr) and IIIAB irons (50-350 $\mathrm{K} / \mathrm{Myr}$ ) are difficult to explain in a common core scenario, and have been interpreted by some to suggest that the PMG and IIIAB irons ultimately formed on separate bodies (Yang et al., 2010). Chemical and isotopic similarities have also been noted for the ungrouped Milton pallasite and the 
South Byron Trio (SBT) iron meteorites, although it is problematic to relate Milton chemically to the SBT core without mixing with metal from a secondary source (Hilton et al., 2019; McCoy et al., 2019).

In addition to the PMG-IIIAB and Milton-SBT associations, chemical similarities, including elevated Ge/Ga ratios of metal, have been noted for the IIF iron meteorites and Eagle Station pallasites (PES) (Kracher et al., 1980) (Fig. 1). Iron meteorites typically have Ge/Ga ratios of $<4$ (Lovering et al., 1957), while both the IIF irons and PES metal are characterized by unusually high ratios near 14 (Kracher et al., 1980). From a limited suite of siderophile element abundances, Kracher et al. (1980) concluded that the IIF irons and PES likely formed on chemically similar parent bodies. Both groups have subsequently been determined to have had identical genetic Mo isotopic compositions, consistent with a common formational environment or even parent body (Dauphas et al., 2002; Burkhardt et al., 2011; Kruijer et al., 2017; Worsham et al., 2019). Further, similar cooling rates for the IIF irons and PES of 1-5 K/Myr (Rasmussen et al., 2001) and 15 K/Myr (Yang et al., 2010), respectively, have also been reported, highlighting additional similarities in the origins of the groups.

The IIF iron meteorite group ostensibly consists of 7 members (Dorofeevka, Del Rio, Monahans (1938), Repeev Khutor, Corowa, Purmela, and Balambala), which are grouped based on similar chemical compositions of certain siderophile elements (Kracher et al., 1980; Connolly et al., 2006; Meteoritical Bulletin 109, in prep). The PES consists of 5 pallasites (Eagle Station, Cold Bay, Itzawisis, Karavannoe and Oued Bourdim 001) that have been grouped based on chemical compositions of metal, fayalite content of olivine of $\sim 20$, and unusual ${ }^{16} \mathrm{O}$-rich oxygen isotopic compositions $\left(\Delta^{17} \mathrm{O}=-4.68 \%\right.$ o) of olivines (Scott, 1977c; Clayton and Mayeda, 1996; Wasson and Choi, 2003; Korochantsev et al., 2013; Humayun et al., 2014; Bouvier et al., 2017). 
In this study, we analyze 6 IIF irons and all 5 PES for abundances of 16 siderophile element abundances and Re-Os isotope systematics. The chemical compositions of the IIF iron meteorites and PES are revisited in order to further investigate the origins of these chemically and isotopically similar meteorite groups, and explore possible relationships between the groups.

\section{Materials and Methods}

Chunks of Eagle Station, Cold Bay, Corowa, and Del Rio, and a polished section of Itzawisis (USNM 7796a) were obtained from the Division of Meteorites, Department of Mineral Sciences, Smithsonian Institution. A chunk of Karavannoe was obtained from the Maine Mineral and Gem Museum. Chunks of Dorofeevka and Repeev Khutor were obtained from the Committee on Meteorites at the Russian Academy of Sciences, and Oued Bourdim 001, Monahans (1938) and Purmela were obtained from the Center of Meteorite Studies at Arizona State University.

All 6 IIF irons and 4 PES (our sample of Cold Bay was fully consumed earlier by the bulk analysis) were analyzed for siderophile element abundances in situ using laser-ablation inductively coupled plasma mass spectrometry (LA-ICP-MS). A New Wave UP213 ultraviolet laser was used, coupled to a Thermo Finnigan Element 2 at the University of Maryland (UMd), following similar methods reported by Walker et al. (2008). Absolute concentrations were obtained from comparison with in-house laboratory reference iron meteorites Coahuila, North Chile, and Hoba. Data normalization was achieved using Ni concentrations reported by Wasson (1969), Scott and Wasson (1976), Scott (1977c), Connolly et al. (2006), Humayun et al. (2014), and Bouvier et al. (2017). Concentrations of $\mathrm{Fe}, \mathrm{Ni}$, and $\mathrm{Co}$ were then totaled to $100 \%$ and concentrations of other siderophile elements were calculated relative to this total. Average concentrations and 1SD uncertainties for 2 to 8 laser ablation tracks from each meteorite were determined. 
With the exception of Itzawisis, concentrations of highly siderophile elements (HSE; Re, Os, Ir, Ru, Pt, Pd) and ${ }^{187} \mathrm{Re}-{ }^{187} \mathrm{Os}$ isotopic data were determined for each meteorite using the isotope dilution method discussed by Walker et al. (2008). Approximately 30 to $90 \mathrm{mg}$ metal pieces of each meteorite were cut from meteorite chunks, when necessary, using a water-cooled Leco Varicut saw and a $12.7 \mathrm{~cm}$ diamond-wafering blade. These masses and corresponding volumes were interpreted to be sufficiently large to avoid heterogeneous sampling of kamacite and taenite, between which the HSE may partition differently (Hirata and Nesbitt, 1997), because most IIF irons have kamacite spindle bandwidths between 50 to $200 \mu \mathrm{m}$, Purmela has a bandwidth of $<2$ $\mathrm{mm}$, and the PES have kamacite bandwidths of $35 \mu \mathrm{m}$ to $1 \mathrm{~mm}$ (Buchwald, 1975; Connolly et al., 2006; Korochantsev et al., 2013; Bouvier et al., 2017). Blocks of SiC were cut prior to cutting each meteorite in order to clean the blade. Each cut meteorite piece was polished using a range of coarseto fine-grit $\mathrm{SiC}$ sandpaper to remove sawblade marks, then sonicated in ethanol to remove sawing and polishing residue. Clean separates of metal and silicate were achieved for all processed PES except Karavannoe, which contained some fragments of olivine that were sufficiently small that they could not be separated from metal. As such, 3 pieces of Karavannoe were processed to constrain the bulk metal's Re-Os isotopic composition.

Metal pieces of each meteorite were combined in a Pyrex ${ }^{\circledR}$ Carius tube with $5 \mathrm{ml}$ of concentrated $\mathrm{HNO}_{3}, 2.5 \mathrm{ml}$ of concentrated $\mathrm{HCl}$, a platinum-group element spike $\left({ }^{191} \mathrm{Ir},{ }^{99} \mathrm{Ru},{ }^{194} \mathrm{Pt}\right.$, and $\left.{ }^{105} \mathrm{Pd}\right)$, and a Re-Os spike $\left({ }^{185} \mathrm{Re}\right.$ and $\left.{ }^{190} \mathrm{Os}\right)$. Tubes were sealed and heated for at least $24 \mathrm{~h}$ at $240{ }^{\circ} \mathrm{C}$ (Shirey and Walker, 1995). The tubes were allowed to cool, opened and solutions were transferred to centrifuge tubes, containing $\mathrm{CCl}_{4}$. Osmium was extracted using the $\mathrm{CCl}_{4}$ solventextraction method of Cohen and Waters (1996) and then Os was purified using a microdistillation procedure (Birck et al., 1997). Spiked Os samples were analyzed by a Thermo-Fisher Triton 
thermal ionization mass spectrometer to determine Os concentrations and ${ }^{187} \mathrm{Os} /{ }^{188} \mathrm{Os}$ ratios (Walker et al., 2008). Osmium isotopic data were corrected for instrumental and natural massfractionation by normalizing ${ }^{192} \mathrm{Os} /{ }^{188} \mathrm{Os}$ to 3.08271 (Allègre and Luck, 1980).

The other HSE were separated and purified using an anion column procedure, then $\mathrm{Re}$ and $\mathrm{Ru}$ separates were further purified using an additional anion column (Walker et al., 2008). The HSE solutions were evaporated to dryness and dissolved in $0.8 \mathrm{~N} \mathrm{HNO}_{3}$. Aliquots for Re analyses were doped with $\mathrm{W}$ in order to correct for instrumental mass bias. Final solutions were measured using a Thermo-Fisher Neptune Plus multi-collector inductively-coupled plasma mass spectrometer at UMd, except for Eagle Station and Cold Bay, which were analyzed using a Nu Plasma multicollector inductively-coupled plasma mass spectrometer, also at UMd. The blanks $(\mathrm{n}=3)$ for these methods ranged from 1 to 3,3 to 5,1 to 2,3 to 80,5 to 6 , and 2 to $500 \mathrm{pg} \mathrm{Re}, \mathrm{Os}$, Ir, Ru, Pt, and Pd, respectively, which have an inconsequential effect on the reported concentrations.

With the exception of Karavannoe, the uncertainties for Re and Os abundances were estimated to be $\leq 0.3 \%$ and $\leq 0.2 \%$, respectively, and the abundances of Ir, Ru, Pt, and Pd were estimated to be $<3 \%$ based on the reproducibility of Monahans (1938) from this study and the reproducibility of other iron meteorites analyzed using identical techniques by past studies (Walker et al., 2008; Worsham et al., 2016). Uncertainties for ${ }^{187} \mathrm{Os} /{ }^{188} \mathrm{Os}$ ratios were estimated to be $\pm 0.1 \%$, and the uncertainties for ${ }^{187} \mathrm{Re} /{ }^{188}$ Os ratios were estimated to be typically $\pm 0.3 \%$. The Re, Os, Ir, Ru, Pt, and Pd abundances of three separately prepared samples of Karavannoe varied by as much as \pm 8 $\%, \pm 5 \%, \pm 6 \%, \pm 6 \%, \pm 5 \%$, and $\pm 9 \%$, respectively, and as little as $\pm 1 \%, \pm 1 \%, \pm 1 \%, \pm 0.2 \%$, $\pm 0.1 \%$, and $\pm 1 \%$, respectively. The Re/Ir, Os/Ir, Ru/Ir, Pt/Ir, and Pd/Ir ratios of the replicates of Karavannoe varied from 0.4 to $3 \%, 0.1$ to $0.4 \%, 0.3$ to $1 \%, 0.2$ to $0.8 \%$, and 2 to $4 \%$, respectively. The larger variations for absolute and relative abundances of HSE of Karavannoe 
compared to the uncertainties cited for the other meteorites were interpreted to be the product of the incomplete separation of metal and silicate, which had the effect of variably diluting the concentrations of HSE in the metal as well as heterogeneously sampling inclusions, such as troilite, within olivine (Korochantsev et al., 2013). Since the silicate inclusions may affect the interpretation of the HSE abundances determined by isotope dilution, the HSE abundances of Karavannoe metal obtained by LA are used in subsequent comparisons of chemical comparisons.

\section{Results}

Siderophile element abundances determined by LA-ICP-MS for the IIF irons and PES are reported in Table 1. Average concentrations generally agree with those reported by past studies within $20 \%$, with a few values differing as much as $150 \%$ (the three greatest deviations are 150 $\%, 83 \%$ and $44 \%$, observed for $\mathrm{W}$ - Corowa, Re - Corowa, and As - Itzawisis, respectively) (Wasson, 1969; Scott and Wasson, 1976; Scott, 1977c; Connolly et al., 2006; Bouvier et al., 2017). Highly siderophile element abundances, determined by isotope dilution, are reported in Table 2 . Abundances of HSE typically agree with those determined by LA-ICP-MS within associated $2 \sigma$ uncertainties. Some IIF iron meteorites have concentrations of certain elements that vary outside of $2 \sigma$ uncertainties by as much as $15 \%$ (the three greatest deviations are $15 \%, 10 \%$ and $9 \%$, observed for Pd - Corowa, Os - Corowa, and Pd - Del Rio, respectively).

Rhenium-Os isotopic data are also reported in Table 2. The IIF irons are characterized by a moderate range of ${ }^{187} \mathrm{Re} /{ }^{188} \mathrm{Os}$ and ${ }^{187} \mathrm{Os} /{ }^{188} \mathrm{Os}$ ratios of 0.3675 to 0.5901 and 0.12444 to 0.14315 , respectively. The PES are characterized by a smaller range in ${ }^{187} \mathrm{Re} /{ }^{188} \mathrm{Os}$ and ${ }^{187} \mathrm{Os} /{ }^{188} \mathrm{Os}$ ratios of 0.3654 to 0.4836 and 0.12477 to 0.13456 , respectively. When regressed using ISOPLOT (Ludwig, 2003), the ${ }^{187} \mathrm{Re}^{187} \mathrm{Os}$ systematics of the IIF iron meteorites and PES form isochrons that yield 
ages of $4.861 \pm 0.310 \mathrm{Ga}(\mathrm{MSWD}=23)$ and $4.416 \pm 1.300 \mathrm{Ga}(\mathrm{MSWD}=134)$, respectively. The IIF irons and PES have $E_{O s}$ values ranging from $+1 \pm 2$ to $+25 \pm 2$, calculated as the part per 10,000 deviation from the ${ }^{187} \mathrm{Os} /{ }^{188} \mathrm{Os}$ ratio of a sample to a $4.568 \mathrm{Ga}$ reference isochron, assuming an initial Solar System ${ }^{187} \mathrm{Os} /{ }^{188} \mathrm{Os}=0.09517$ and $\lambda=1.666 \times 10^{-11} \mathrm{yr}^{-1}$ (Smoliar et al., 1996; Archer et al., 2014).

\subsection{Re-Os chronometry}

The ${ }^{187}{ }^{R e}-{ }^{187}$ Os chronometer, in which ${ }^{187} \operatorname{Re}$ decays to ${ }^{187}$ Os by $\beta^{-}$emission with a half-life of 41.6 Gyr (Smoliar et al., 1996), can be used to broadly constrain the age of metal crystallization for iron meteorites and pallasites. Application of this chronometer typically results in associated uncertainties of >10 Myr (e.g., Smoliar et al., 1996; Chen et al., 2002; Walker et al., 2008; McCoy et al., 2011). The large uncertainties for the IIF irons and PES isochrons ( $\pm>100 \mathrm{Myr}$ ) reflect both the limited number of meteorites for each isochron and minor open system behavior for some meteorites. Here, the Re-Os systematics are compared to a chondritic 4.568 Ga reference isochron in order to assess whether iron meteorite and pallasite metals have maintained closed-system behavior since crystallization, assuming crystallization within the first 10-20 Ma of Solar System history. The IIF iron meteorites and PES all fall within \pm 25 part per 10,000 of a 4.568 Ga reference isochron (Fig. 2), indicating that most of the iron meteorites and pallasites examined maintained closed-system behavior of Re and Os, and presumably the other HSE, since crystallization in the early Solar System. The largest deviation of $+25 \pm 2$ was determined for Cold Bay, of which our piece was highly rusted (Scott, 1977c). 


\subsubsection{Group background}

Wasson (1969) reported similar Ni, Ga, Ge, and Ir abundances for Corowa and Monahans (1938), leading to the suggestion that the 2 meteorites may be related. Subsequent publication of $\mathrm{Ni}, \mathrm{Ga}, \mathrm{Ge}$, and Ir abundances for Dorofeevka, Del Rio, and Repeev Khutor by Scott and Wasson (1976) led to the interpretation that Dorofeevka, Del Rio, and Monahans (1938) should be considered an iron trio, and that Repeev Khutor and Corowa may be a possible iron duo. This idea was then modified by Kracher et al. (1980) after measuring these 5 irons for abundances of additional siderophile elements, including $\mathrm{Co}, \mathrm{Cu}, \mathrm{As}, \mathrm{W}, \mathrm{Re}$, and $\mathrm{Au}$. Kracher et al. (1980) concluded that these irons should be designated as a new iron meteorite group termed the IIF irons. Purmela was later analyzed for Ni, Co, Ga, As, and Ir abundances (Connolly et al., 2006), and classified as the sixth member of this group. Balambala was classified as the seventh IIF iron, based on its $\mathrm{Ge} / \mathrm{Ga}$ ratio and abundances of other siderophile elements that fall within the ranges observed for other IIF irons (Meteoritical Bulletin 109, in prep). Most IIF iron meteorites are classified as plessitic octahedrites while Del Rio is an ataxite (Buchwald, 1975). The IIF iron meteorites commonly contain kamacite, taenite, schreibersite, and troilite. Chromite and graphite were observed in the meteorites Monahans (1938) and Del Rio, respectively, as reported by Buchwald (1975).

\subsubsection{Chemical characteristics of IIF irons}

Siderophile element abundances determined by LA-ICP-MS for 6 IIF irons are compared in Fig. 3. Large variations (200 to 4,000 \%) are observed in the abundances of Re, Os, W, Ir, Ru, Pt, $\mathrm{As}, \mathrm{Au}$, and $\mathrm{Ge}$, while moderate variations (4 to $100 \%$ ) are observed for $\mathrm{Mo}, \mathrm{Rh}, \mathrm{Ni}, \mathrm{Co}, \mathrm{Fe}, \mathrm{Pd}$, 
$\mathrm{Cu}$, and Ga. Kracher et al. (1980) interpreted the variations in siderophile element abundances in IIF irons to be a result of fractional crystallization in a common core. The variations observed here are broadly consistent with those observed for other iron groups and grouplets interpreted to be products of fractional crystallization (i.e. SBT, IVA, and IVB), measured using similar techniques (Walker et al., 2008; McCoy et al., 2011, 2019), consistent with this interpretation. If an interpretation of fractional crystallization is correct, the degree of variations for the element concentrations of IIF irons must reflect the extent of crystal-liquid fractionation and changing partition coefficients (D values) of these elements between solid metal and liquid metal during fractional crystallization, with major variations of certain element abundances reflecting highly compatible (D values $>>1$ ) or incompatible behavior (D values $<<1$ ) and moderate variations reflecting D values closer to 1 .

Germanium and Ga are 2 siderophile elements that are little affected by metal crystal-liquid fractionation processes because of their solid metal-liquid metal D values close to 1 (e.g., Chabot et al., 2017). The Ge/Ga ratios for most of the IIF irons of between 11 to 16 reported here are consistent with the ratios of 11 to 17 reported by Kracher et al. (1980). The ratio of $\sim 3$ for Purmela, however, is considerably outside the range of the other IIF irons (Fig. 1). This lower ratio is due to a substantially lower $\mathrm{Ge}$ abundance relative to $\mathrm{Ga}$, which has a concentration similar to other IIF irons. Achieving such a low ratio by fractional crystallization or related mixing processes within a system common to the other IIF irons is difficult to envision by fractional crystallization. As such, this chemical difference suggests that Purmela may not be a IIF iron and may instead derive from a different parent body with a similar, but not identical bulk chemical composition.

\subsubsection{Fractional crystallization modeling}


An origin of the IIF irons by fractional crystallization can be further evaluated by comparison of the high precision HSE bulk concentration data (Fig. 3), obtained by isotope dilution, to fractional crystallization models (e.g., Walker et al., 2008; McCoy et al., 2011; Hilton et al., 2019). To do this, we use the parameterization method discussed by Chabot et al. (2017) for calculating solid metal-liquid metal D values during fractional crystallization. This approach is necessary as $D$ values of siderophile elements typically vary depending on the $S, P$, and/or $C$ content of a liquid (e.g., Jones and Malvin, 1990, Chabot and Jones, 2003; Worsham et al., 2016). The approach used here treats the initial S, P, C, and HSE contents of a liquid as free parameters, and the D values of $\mathrm{P}, \mathrm{C}$, and the HSE are calculated as the initial $\mathrm{S}, \mathrm{P}$, and $\mathrm{C}$ contents are varied, based on experimentally-derived S/P/C abundance $v s$. D value relationships (Chabot et al., 2017). Changes in the D values for each element are calculated at each $0.1 \%$ of fractional crystallization, as the progressive changes in $\mathrm{S}, \mathrm{P}$, and $\mathrm{C}$ content of the liquid occurs. The initial abundances of $\mathrm{S}, \mathrm{P}, \mathrm{C}$, and HSE are varied iteratively until a fractional crystallization sequence is determined that best accounts for the chemical abundances of a certain meteorite group. Equilibrium solid and liquid HSE compositions predicted for fractional crystallization in systems with various $\mathrm{S}$ contents using this approach are shown in Fig. 4 for reference. Additional details about the fractional crystallization modeling calculations are provided in the supplementary information.

For magmatic iron meteorite groups, fractional crystallization models of the cores from which they derive may be constrained by identifying at least 2 iron meteorites that formed as equilibrium solids from the same fractional crystallization sequence (e.g., Hilton et al., 2019). This is not possible for the IIF iron meteorites, however, indicating that a single fractional crystallization model cannot presently be constrained. For example, the Pd vs. Re systematics of Monahans (1938) and Repeev Khutor can be accounted for as equilibrium solids in a system with 3 wt. \% S, 
but their Pt/Os vs. Pt systematics require 16 wt. \% S. Similarly, Dorofeevka and Monahans (1938) have Pd vs. Re systematics that match equilibrium solids produced in a system with 16 wt. \% S but their Pt/Os vs. Pt systematics require 3 wt. \% S. Here, Pd is an especially important siderophile element to model. Of the HSE measurable to high precision by isotope dilution, it is typically the only incompatible element. Consequently, the initial core concentration of Pd for an iron meteorite group usually must be greater than the lowest concentration for any of the meteorites from that group.

In order to further investigate the origins of the IIF iron meteorites, we anchor all fractional crystallization models against the composition of Monahans (1938). This meteorite is assumed to be an equilibrium solid since it has the lowest concentration of Pd, and modeling attempts using any other IIF meteorite fail to account for the HSE systematics of other IIF irons. Given the limitless number of models that can produce Monahans (1938) as an equilibrium solid resulting from fractional crystallization, we restrict the possible models to those with parental melt compositions with relative abundances of HSE within the ranges observed in carbonaceous chondrites (Horan et al., 2003; Fischer-Gödde et al., 2010). Carbonaceous chondrites are chosen here because they are most similar to the IIF iron meteorites with respect to genetic isotope compositions (e.g., Budde et al., 2019). A range of parental melt compositions (Table 3) is constrained based on these assumptions and shown in Fig. 6. The IIF Model 1 (M1) assumes initial $\mathrm{S}=13$ wt. $\%$ and a parental melt $\mathrm{Pd} / \mathrm{Ir}$ ratio that is in the middle of the range observed in carbonaceous chondrites. Model 2 (M2), assuming initial $\mathrm{S}=11$ wt. \%, and Model 3 (M3), assuming initial $\mathrm{S}=15 \mathrm{wt} . \%$, have $\mathrm{Pd} / \mathrm{Ir}$ ratios that are at the extremes of the $2 \mathrm{SD}$ range observed in carbonaceous chondrites. 
Changing the $\mathrm{S}$ content to $>15$ wt. $\%$ or $<11$ wt. \% requires parental melts with relative abundances of $\mathrm{Pd}$, compared to the other HSE, that are outside the ranges observed in carbonaceous chondrites (Pd depleted and Pd enriched, respectively). A Pd depletion relative to the other HSE was constrained for the IVB iron meteorite parental melt (Campbell and Humayun, 2005; Walker et al., 2008), but it was coupled with observed depletions for volatile elements. The IIF irons are volatile-rich compared to the IVB irons, making a relative depletion in Pd composition due to volatility unlikely. Worsham et al. (2016) observed, for the parental melt of the IAB-sLM iron meteorite subgroup, a Pd enrichment relative to other HSE, which was suggested to reflect fractionation of refractory elements by a volatility-driven process. However, the IIF irons do not exhibit depletions in other refractory elements (e.g., Mo; Fig. 3), making this explanation for the IIF irons also unlikely.

The HSE parental melt compositions constrained using M1 and M2 fall between estimated bulk core compositions of the IIC, IVA, and SBT iron meteorites (Fig. 6), whereas the HSE parental melt composition resulting from M3 is similar to that of the IVA iron meteorites (Walker et al., 2008; McCoy et al., 2011; Hilton et al., 2019; Tornabene et al., 2020). The HSE parental melt compositions of M1, M2, and M3 are enriched compared to the average HSE abundances of carbonaceous chondrites by factors of 4 to 10 . These enrichment factors suggest that if the IIF irons formed from a body with a bulk composition similar to carbonaceous chondrites, the IIF parental melt was between 10 and $22 \%$ the mass of the body.

\subsubsection{IIF iron meteorite origin scenarios}

The IIF iron meteorites cannot all be related as equilibrium solids resulting from the same simple fractional crystallization sequence, as they do not define a linear trend on plots of HSE $v s$. 
HSE. It is consequently instructive to compare their variations in chemical compositions to the IIIAB iron meteorite group, which is one of the most frequently studied magmatic iron meteorite groups. The IIIAB, similarly consists of numerous members that cannot be interpreted to be equilibrium solids resulting from simple fractional crystallization. Past studies have proposed a variety of pathways to explain the chemical complexities of the IIIAB irons, including mixing of residual metal from the mantle into a partially crystallized core (Pernicka and Wasson, 1987), separation of the core into isolated, separate magma chambers by early dendrites formation (Haack and Scott, 1993), crystallization from immiscible liquids (Ulff-Møller, 1998), equilibrium mixing of solids and trapped liquids by diffusion (Wasson, 1999; Chabot, 2019), and non-equilibrium mixing of primitive solids with evolved liquids (Cook et al., 2004).

Compared to M1, Dorofeevka, Del Rio, and Repeev Khutor have HSE abundances that fall between the solid metal and liquid metal evolution curves (Fig. 7), permissive of forming by equilibrium solid metal-liquid metal mixing. This process was proposed by Wasson (1999) to explain the formation of certain IIIAB iron meteorites. For this process to occur, some crystallizing solids must trap equilibrium liquids, which then become chemically mixed by diffusion. Corowa, however, has Re/Os vs. Re and Pt/Os vs. Pt systematics that fall to the left of the solid metal and liquid metal evolution curves (Fig. 7), indicating that it cannot be a product of equilibrium solid metal-liquid metal mixing.

The HSE abundances of Dorofeevka, Del Rio, and Repeev Khutor can also be explained by non-equilibrium mixing of primitive solids with evolved liquids. This process was proposed by Cook et al. (2004) to explain the Re/Os vs. Re and Pt/Os vs. Pt systematics of certain IIIAB iron meteorites that fall within and to the left of the solid metal and liquid metal evolution curves of that study's favored IIIAB fractional crystallization model. As such, this mechanism can also 
produce the Re/Os vs. Re and Pt/Os vs. Pt systematics of Corowa (Fig. 8). Non-equilibrium mixing of evolved liquid with earlier formed solids may have been achieved by the fracturing of a crystallizing core, followed by mobilization of the evolved melt throughout the fractures. The primitive solid and evolved liquid may then have equilibrated by diffusion, or by melting of the solid, mixing with the liquid, and re-crystallization. Fractures to a crystallizing core may be formed through impact to the parent body. Alternatively, as suggested by Cook et al. (2004), similar compositions may also be produced by the detachment of crystallized metal from the ceiling of a magma chamber and infiltration of evolved liquid into the resulting cavity.

The late segregation of metal melts from the mantle to a residual liquid outer core (Pernicka and Wasson, 1987; Smoliar, 1996; Cook et al., 2004) can also account for the HSE abundances of Dorofeevka, Del Rio, Repeev Khutor, and Corowa. Pernicka and Wasson (1987) suggested that intermittent segregation of a metallic melt, which would likely be enriched in HSE, to an outer liquid core could alter the composition of highly compatible elements, like Re and Os, in liquid during crystallization. For example, adding $5 \%$ of a late-segregated liquid with a composition of the bulk core to the liquid core after $40 \%$ of crystallization results in a significant shift in the Re/Os vs. Re systematics of the liquid core and subsequent crystallizing metal (Fig. 8).

One additional mechanism to consider as a means of generating the variations in HSE abundances among the IIF irons is the crystallization of dendrites in a core. Haack and Scott (1992, 1993) argued that convection of the liquid core during inward dendritic crystallization could heterogeneously distribute chemically distinct liquids between dendrites, resulting in non-uniform crystallization of metal. Such liquids could be the products of incomplete mixing of a core prior to crystallization or the formation of immiscible liquids during crystallization (Ulff-Møller, 1998). Additionally, changes to the convection patterns of the core with increasing dendrite growth could 
cause additional non-equilibrium mixing of these chemically distinct liquids. Mixing between a liquid with a composition after $10 \%$ crystallization with a liquid with a composition after $40 \%$ crystallization, for example, can result in metal compositions to the left of a given Re/Os $v s$. Re fractional crystallization field (Fig. 8). This mechanism was envisioned by Haack and Scott (1993) to explain the deviations of the chemical compositions of some IIIAB iron meteorites from simple fractional crystallization models and may also explain the IIF irons as well. Discerning between non-equilibrium solid metal-liquid metal mixing, late segregation of liquid metal, and dendritic crystallization may ultimately require the classification and chemical study of additional IIF iron meteorites.

\subsection{Eagle Station pallasites}

\subsubsection{Group background}

Eagle Station was recognized by Wasson and Sedwick (1969) for its distinct chemical composition compared to the PMG, warranting its own classification. Scott (1977c) applied this classification to Itzawisis and Cold Bay, and dubbed the three pallasites the Eagle Station Trio. The metal in these pallasites were characterized as having greater Ni and Ge contents, as well as lesser Ga contents, than the metal in the PMG, and the olivine in the Eagle Station Trio had a greater fayalite content than the olivine in the PMG (Scott, 1977c). Additionally, the metal and olivine in the Eagle Station Trio were later determined to be isotopically distinct from the PMG using $\mathrm{O}$ and Mo as genetic tracers (Clayton and Mayeda, 1996; Dauphas et al., 2002; Burkhardt et al., 2011). Karavannoe and Oued Bourdim 001 have since been added to this Trio (Korochantsev et al., 2013; Humayun et al., 2014; Bouvier et al., 2017), bringing the total number of PES members to 5, the minimum number required for official group status (Wasson, 1974). The PES similarly 
contain kamacite, taenite, schreibersite, and troilite, as well as chromite and olivine (Wasson and Choi, 2003; Korochantsev et al., 2013; Bouvier et al., 2017).

It has been proposed that the PES either formed at the core-mantle boundary of a planetesimal, or as a result of 2 impacts (Malvin et al., 1985; Davis and Olsen, 1991). Malvin et al. (1985) proposed an origin through impacts based on the relatively high Ir content of the PES metal. The high Ir was interpreted to mean that the PES did not represent the core-mantle boundary based on the assumption that if a core crystallized from the center outwards, it would produce an outer core with relatively low Ir concentrations. Instead, these authors suggested that an initial impact to the PES parent body could have generated enough heat to form a metal-silicate melt. Upon separation into a bottom metal layer, a middle olivine residue layer, and an olivine cumulus layer on top, a second impact fractured the olivine and drove metallic melt throughout the olivine cracks. By contrast, Davis and Olsen (1991) measured the rare earth elements (REE) abundances in phosphates from Eagle Station and explained the compositions through the exchange of REE between olivine and phosphates at the core-mantle boundary. The authors proposed that the olivine present in the PES formed as a cumulate at the bottom of the mantle with a light-REE-depleted composition. Upon mixing with metal from the core, phosphates formed between the metal-olivine interfaces and inherited a light-REE-depleted composition through REE partitioning between olivine and phosphate. A combination of both ideas was proposed by Scott and Taylor (1990), suggesting that the PES, which contain highly angular olivine crystals (Scott, 1977b), formed as a result of impact, which mixed metal and olivine at the core-mantle boundary. Due to the relatively high Ir content of the PES metal, this event was proposed to have occurred prior to core crystallization. 


\subsubsection{Chemical characteristics of PES}

The abundances of 16 siderophile elements determined by LA-ICP-MS in metal from 4 PES are compared in Fig. 3. Major variations ( $>200 \%)$ are observed in the abundances of Re, Os, and Ir among these pallasites, and more moderate variations (5 to $100 \%$ ) are observed for $\mathrm{W}, \mathrm{Mo}, \mathrm{Ru}$, $\mathrm{Pt}, \mathrm{Rh}, \mathrm{Ni}, \mathrm{Co}, \mathrm{Fe}, \mathrm{Pd}, \mathrm{As}, \mathrm{Au}, \mathrm{Cu}, \mathrm{Ga}$, and $\mathrm{Ge}$. Given the range of Re, Os, and Ir abundances observed for the PES, some fractional crystallization of the PES parental melt is apparent. The PES metal is characterized by relative depletions in $\mathrm{W}$ abundances compared to the abundances of other refractory siderophile elements, such as Os and Ir. This observation may reflect a comparatively high oxidation state of the PES parent body, an explanation that has been applied to similar depletions observed for some iron meteorites, such as the SBT (McCoy et al., 2019). Tungsten is redox sensitive and more likely to be retained by the mantle of an oxidized body. A relatively high oxidation state for the PES parent body has also been inferred from the high fayalite content of olivine and the high Ni content of the metal (Scott, 1977c). Itzawisis and Eagle Station have $\mathrm{Ge} / \mathrm{Ga}$ ratios of 15 and 14, respectively, which are consistent with the ratios reported by Scott (1977c) of 15 and 17, respectively. Oued Bourdim 001 has a Ge/Ga ratio of 15 and Karavannoe has a $\mathrm{Ge} / \mathrm{Ga}$ ratio of 12 .

\subsubsection{Fractional crystallization modeling}

As with the IIF irons, the relationship among metal for the PES can be assessed by fractional crystallization modeling. Unlike the IIF irons, the PES metal form clear trends for HSE abundances, which can broadly be accounted for as equilibrium solids produced by fractional crystallization of a parental melt with $550 \mathrm{ppb}$ Re, $7000 \mathrm{ppb}$ Os, $6700 \mathrm{ppb}$ Ir, $10000 \mathrm{ppb}$ Ru, 12500 ppb Pt, 6800 ppb Pd, 6 wt. \% S, and 0.7 wt. \% P, PES Model 1 (PES M1) (Fig. 6). The PES metal 
compositions fall among compositions predicted for the first $\sim 50 \%$ of fractional crystallization from this parental melt (Fig. 9). Some shortcomings are apparent for this model, however, including Cold Bay for Re/Os vs. Re and Pd vs. Re and Karavannoe for Pt/Os vs. Pt. These variations may indicate some solid metal-liquid metal mixing affected the composition of these meteorites, however, any such mixing would likely affect the abundances of the other HSE as well. The HSE parental melt composition projected from this PES fractional crystallization sequence has relative abundances of HSE that are within the ranges observed in carbonaceous chondrites, to which the PES are genetically linked (Horan et al., 2003; Fischer-Gödde et al., 2010; Budde et al., 2019). The absolute abundances are enriched compared to those of average carbonaceous chondrites by a factor of 11 (Fig. 6), which suggests that the parental metallic melt to the PES was $\sim 9 \%$ the mass of the parent body.

\subsubsection{PES origin scenarios}

Given that the PES metal compositions can be accounted for by $\sim 50 \%$ fractional crystallization of a metallic liquid that was $\sim 9 \%$ the mass of a planetary body, our preferred interpretation is that the PES metal was derived from the core of the PES parent body. Given the broad adherence to a model of fractional crystallization, this core likely crystallized concentrically. Haack and Scott (1992) argued that during crystallization, S-rich melts would build up at the solid-liquid boundary layer, resulting in liquid heterogeneities. Crystallization would then preferentially progress in areas with less S contents, resulting in the growth of dendrites. However, if these dendrites were on the meter scale, dendritic crystallization may have resembled concentric crystallization (Haack and Scott, 1992). Formation of meter-scale dendrites may also help to explain the slight variations of certain HSE from the best fit model. 
The occurrence of olivine throughout at least $50 \%$ of a crystallized core is difficult to envision given the density differences among metal and olivine. This is especially unlikely to occur if the core was crystallizing from the center outward. Co-mingling of olivine and liquid metal may be possible, however, if the olivine was prevented from separating from a metallic liquid by a solid outer metallic rim (Fig. 10). This scenario may be plausible in an inward crystallizing core, which may also have forced the olivine further inward while also trapping some olivine in solid metal during crystallization. The initial mixing event of liquid metal and olivine to form pallasites has been envisioned by numerous studies to be the result of impact (e.g., Malvin et al., 1985; Scott and Taylor, 1990; Yang et al., 2010; Wasson, 2016). The angular olivine textures in the PES have also been interpreted as evidence for impact (Scott and Taylor, 1990). If impact did cause olivine to infiltrate a liquid core, it is plausible that the outer core crystallized quickly, given the contact with circulating colder mantle materials, thus trapping the infiltrated olivine and preventing density separation.

\subsection{IIF vs. PES parent bodies}

The chemical similarities between the IIF irons and PES metal were noted by Scott (1977c) based on $\mathrm{Ge} / \mathrm{Ga}$ ratios. This study concluded that any genetic link between the 2 meteorite groups was "tenuous" unless chemical trends were better defined. It was also noted that the reported cooling rates for some IIF irons were factors of 20 to 75 times that of metal in Eagle Station. More similar cooling rates for the IIF irons and PES of 1-5 K/Myr (Rasmussen et al., 2001) and 15 K/Myr (Yang et al., 2010), respectively, subsequently have been reported.

Additional chemical comparisons were made between the IIF irons and PES by Kracher et al. (1980). These authors noted that the abundances of Re, Ir, As, and Au of the PES metal fall within 
the ranges observed for IIF metal but that the PES have greater abundances of $\mathrm{Co}$ and $\mathrm{Ni}$ as well as lower abundances of $\mathrm{Ga}$ and $\mathrm{Ge}$, compared to the IIF irons. Since these chemical dissimilarities were greater than observed for the IIIAB irons and PMG, Kracher et al. (1980) concluded the IIF irons and PES were less likely to originate from the same body than the IIIAB-PMG. Nevertheless, Kracher et al. (1980) noted that the 2 groups warranted association, and that they likely formed in chemically similar parent bodies. Measurements of genetic Mo isotopic compositions for the PES (Dauphas et al., 2002; Burkhardt et al., 2011) and the IIF irons (Kruijer et al., 2017; Worsham et al., 2019) indicate that these were isotopically similar bodies as well.

The new composition data reported here support the conclusions of Kracher et al. (1980) that the IIF irons and the PES are from chemically similar bodies. For example, the PES have HSE abundances that fall within the range of the IIF irons (Fig. 7), permissive of an association between the PES and the IIF core. Yet the key differences in the chemical compositions of the PES and IIF irons noted by Kracher et al. (1980) remain difficult to reconcile. Specifically, the PES are systematically enriched in Ni by $\sim 4$ wt. $\%$ and depleted in Ga and Ge by $\sim 3$ ppm and $\sim 46$ ppm, respectively, compared to the IIF irons. Nickel enrichment can occur in a bulk core of an oxidized parent body, resulting from the increased incorporation of oxidized Fe in the mantle, compared to a more reduced body. Variable enrichment of this sort, however, would not occur on a single body. The lower W of the PES, compared to the IIF irons (Fig. 3) is consistent with an interpretation that the PES parent body was more oxidized than the IIF parent body. Nickel enrichment of the magnitude required to account for differences between the IIF irons and the PES could also occur as a result of extensive crystal-liquid fractionation, i.e. as observed in the group IIIAB irons. However, extensive crystal-liquid fraction would also be accompanied by other chemical characteristics, including large ranges in the concentrations of highly compatible HSE, such as Ir 
483

and Os, which are not observed. Similar conclusions can be reached regarding $\mathrm{Ga} / \mathrm{Ni}$ and $\mathrm{Ge} / \mathrm{Ni}$ ratios. Collectively, these observations argue against a common parent body for the PES and IIF irons, consistent with the conclusions of Kracher et al. (1980). However, chemical similarities, as well as genetic isotopic compositions suggest that the 2 groups formed on similar parent bodies that likely formed in the solar nebula in the same general vicinity and possibly at the same time in nebular evolution.

\section{Conclusions}

Study of the siderophile element abundances present in metal in IIF irons and PES provides permissive evidence for each of derivation from a planetesimal core. The HSE compositions of the PES suggest these meteorites primarily formed as equilibrium solids while most of the IIF irons require substantial solid metal-liquid metal mixing. The presence of olivine in the PES can be explained through impact-driven intrusion of olivine into a liquid core, crystallization of the outer core, and subsequent inward crystallization. While the abundances of most siderophile elements examined in the IIF irons and PES can be explained by the formation in a common core, abundances of $\mathrm{W}$ and Ni indicate that the PES ultimately derived from a more oxidized body than the IIF irons. 
501 We gratefully acknowledge the Division of Meteorites, Department of Mineral Sciences, 502 Smithsonian Institution, the Center for Meteorite Studies at Arizona State University, the Maine 503 Mineral and Gem museum, and the Committee on Meteorites, Academy of Sciences, Russia for 504 providing the samples for this study. We also thank Kevin Righter, Andrew Davis, and Joe 505 Boesenberg for their helpful comments that improved the quality of this manuscript. This study 506 was supported by NASA Emerging Worlds grants NNX16AN07G and 80NSSC20K0335 (to 507 RJW). 
Allègre C.J. and Luck J.-M. (1980) Osmium isotopes as petrogenetic and geological tracers. Earth Planet. Sci. Lett. 48, 148-154.

Anders E. (1964) Origin, age, and composition of meteorites. Space Science Reviews 3, 583-714.

Archer G.J., Ash R.D., Bullock E.S., Walker R.J. (2014) Highly siderophile elements and ${ }^{187}$ Re${ }^{187}$ Os isotopic systematics of the Allende meteorite: Evidence for primary nebular processes and late-stage alteration. Geochim. Cosmochim. Acta 131, 402-414

Birck J.-L., Roy-Barman M., Capmas F. (1997) Re-Os isotopic measurements at the femtomole level in natural samples. Geostand. Newslett. 20, 9-27.

Boesenberg J.S., Delaney J.S., Hewins R.H. (2012) A petrological and chemical reexamination of main group pallasite formation. Geochim. Cosmochim. Acta 89, 134-158.

Bouvier A., Gattacceca J., Agee C., Grossman J., Metzler K. (2017) The meteoritical bulletin, No. 104. Meteorit. Planet. Sci. 1, 1-247.

Buchwald V. F. (1975) Handbook of Iron Meteorites. University of California Press, Berkeley, CA.

Burkhardt C., Kleine T., Oberli F., Pack A., Bourdon B. and Wieler R. (2011) Molybdenum isotope anomalies in meteorites: constraints on solar nebula evolution and origin of the Earth. Earth Planet. Sci. Lett. 312, 390-400.

Campbell A. J. and Humayun M. (2005) Compositions of group IVB iron meteorites and their parent melt. Geochim. Cosmochim. Acta 69, 4733-4744.

Chabot N.L., Wollack E.A., McDonough W.F., Ash R.D., Saslow S.A. (2017) Experimental determination of partitioning in the Fe-Ni system for applications to modeling meteoritic metals. Meteorit. Planet. Sci. 52, 1133-1145.

Chabot N.L. (2019) Revised trapped melt model for iron meteorites. $82^{\text {nd }}$ Annual Meeting of The Meteoritical Society, 6025 (abst).

Chen J.H., Papanastassiou D.A., Wasserburg G.J. (2002) Re-Os and Pd-Ag systematics in Group IIIAB irons and in pallasites. Geochim. Cosmochim. Acta 66, 3793-3810.

Clayton, R.N. and Mayeda, T.K. (1996) Oxygen isotope studies of achondrites. Geochim. Cosmochim. Acta 60, 1999-2017.

Cohen A.S. and Waters F.J. (1996) Separation of osmium from geological materials by solvent extraction for analysis by thermal ionization mass spectrometry. Anal. Chim. Acta 332, 269-275. 
Connolly, Jr H.C., Zipfel J., Grossman J.N., Folco L., Smith C., Jones R.H., Righter K., Zolensky M., Russell S.S., Benedix G.K., Yamaguchi A., Cohen B.A. (2006). The meteoritical bulletin, No. 90, 2006 September. Meteorit. Planet. Sci. 41, 1383-1418.

Cook D.L., Walker R.J., Horan M.F., Wasson J.T., Morgan J.W. (2004) Pt-Re-Os systematics of group IIAB and IIIAB iron meteorites. Geochim. Cosmochim. Acta 68, 1413-1431.

Dauphas N., Marty B., Reisberg L. (2002) Molybdenum evidence for inherited planetary scale isotope heterogeneity of the protosolar nebula. Astrophys. Journ. 565, 640-644.

Davis, A.M. and Olsen, E.J. (1991) Phosphate in pallasite meteorites as probes of mantle processes in small planetary bodies. Nature 353, 637-640.

Dottin J.W., Farquhar J., Labidi J. (2018) Multiple sulfur isotopic composotion of main group pallasites support genetic links to IIIAB iron meteorites. Geochim. Cosmochim. Acta 224, 276-281.

Fischer-Gödde M., Becker H., Wombacher F. (2010) Rhodium, gold, and other highly siderophile element abundances in chondritic meteorites. Geochim. Cosmochim. Acta 74, 356-379.

Haack H. and Scott E.R.D. (1992) Asteroid core crystallization by inward dendritic growth. $J$. Geophys. Res. 97, 14727-14734.

Haack H. and Scot E.R.D. (1993) Chemical fractionations in Group IIIAB iron meteorites: Origin by dendritic crystallization of an asteroidal core. Geochim. Cosmochim. Acta 57, 3457-3472.

Hilton C.D., Bermingham K.R., Walker R.J., McCoy T.J. (2019) Genetics, crystallization sequence, and age of the South Byron Trio iron meteorites: New insights to carbonaceous chondrite (CC) type parent bodies. Geochim. Cosmochim. Acta 251, 217-228.

Hirata T. and Nesbitt R.W. (1997) Distribution of platinum group elements and rhenium between metallic phases of iron meteorites. Earth Planet. Sci. Lett. 147, 11-24.

Horan M.F., Walker R.J., Morgan J.W., Grossman J.N., Rubin A.E. (2003) Highly siderophile elements in chondrites. Chem. Geol. 196, 5-20.

Humayun M., Teplyakova S.N., Lorenz C.A., Ivanova M.A., Korochantsev A.V. (2014) Siderophile element abundances in Karavannoe: implications for the origin of the Eagle Station Pallasites. Lunar Planet. Sci. Conf. XLV, 2293 (abst).

Jones J. H. and Malvin D. J. (1990) A nonmetal interaction model for the segregation of the trace metals during solidification of $\mathrm{Fe}-\mathrm{Ni}-\mathrm{S}, \mathrm{Fe}-\mathrm{Ni}-\mathrm{P}, \mathrm{Fe}-\mathrm{Ni}-\mathrm{S}-\mathrm{P}$ alloys. Metall. Trans. B 21B, 697-706. 
Korochantsev A.V., Lorenz C.A., Ivanova M.A., Teplyakova S.N., Kononkova N.N., Roshina I.A., Borisovsky S.E., Bychkova Y.V., Franchi I.A., Greenwood R.C. (2013) Karavannoe: a new member of the Eagle Station Pallasite grouplet. Lunar Planet. Sci. Conf. XLIV, 2020 (abst).

Kracher A., Willis J., Wasson J.T. (1980) Chemical classification of iron meteorites-IX. A new group (IIF), revision of IAB and IIICD, and data on 57 additional irons. Geochim. Cosmochim. Acta 44, 773-787.

Kruijer T.S., Burkhardt C., Budde G., Kleine T. (2017) Age of Jupiter inferred from the distinct genetics and formation times of meteorites. Proc. Natl. Acad. Sci. 114, 6712-6716.

Lodders K. (2003) Solar System abundances and condensation temperatures of the elements. Ap. J. 591, 1220-1247.

Lovering J.F., Nichiporuk W., Chodos A., Brown H. (1957) The distribution of gallium, germanium, cobalt, chromium, and copper in iron and stony-iron meteorites in relation to nickel content and structure. Geochim. Cosmochim. Acta 11, 263-278.

Ludwig K. R. (2003) User's Manual for Isoplot 3.00. Berkeley Geochronology Center Special Publication No. 4, Berkeley, CA, 70 pp.

Malvin D.J., Wasson J.T., Clayton R.N., Mayeda T.K., da Silva Curvello W. (1985) Bocaiuva A silicate-inclusion bearing iron meteorite related to the Eagle-Station pallasites. Meteoritics 20, 259-273.

McCoy T.J., Walker R.J., Goldstein J.I., Yang J., McDonough W.F., Rumble D., Chabot N.L., Ash R.D., Corrigan C.M., Michael J.R., Kotula P.G. (2011) Group IVA irons: new constraints on the crystallization and cooling history of an asteroidal core with a complex history. Geochim. Cosmochim. Acta 75, 6821-6843.

McCoy T.J., Corrigan C.M., Nagashima K., Reynolds V.S., Ash R.D., McDonough W.F., Yang J., Goldstein J.I., Hilton C.D. (2019) The Milton pallasite and South Bryon Trio irons: Evidence for oxidation and core crystallization. Geochim. Cosmochim. Acta 259, 358-370.

Meteoritical Bulletin, No. 109 (in prep). Meteorit. Planet. Sci.

Mittlefehldt D. W. (1980) The composition of mesosiderite olivine clasts and the implications for the origins of pallasites. Earth Planet. Sci. Lett. 51, 29-40.

Rasmussem K.L., Haack H., Ulff-Møller F. (2001) Metallographic cooling rates of group IIF iron meteorites. Meteorit. Planet. Sci. 36, 883-896.

Rayleigh L. (1942) The stone-iron meteorites called pallasites: a synthetic study of their structure and probable mode of formation. Proc. R. Soc. Lond. A 179, 386-393. 
662

663

664

665

666

667

668

669

670

671

672

673

674

675

676

677

678

679

680

681

682

683

684

685

686

687

688 689

Scott E.R.D. (1977a) Geochemical relationships between some pallasites and iron meteorites. Mineralogical magazine 41, 265-272.

Scott E.R.D. (1977b) Formation of olivine-metal textures in pallasite meteorites. Geochim. Cosmochim. Acta 41, 693-710.

Scott E.R.D. (1977c) Pallasites-metal composition, classification and relationships with iron meteorites. Geochim. Cosmochim. Acta 41, 349-360.

Scott E.R.D. and Wasson J.T. (1976) Chemical classification of iron meteorites VIII. Groups IC, IIE, IIIF and 97 other irons. Geochim. Cosmochim. Acta 40, 103-115.

Scott E.R.D. and Taylor J.G. (1990) Origins of pallasites at the core-mantle boundaries of asteroids. Lunar Planet. Sci. Conf. XXI, 1119-1120 (abst).

Smoliar M.I. (1996) Re-Os isotopic study of magmatic iron meteorites. Ph.D. dissertation, University of Maryland, $105 \mathrm{pp}$.

Smoliar M.I., Walker R.J., Morgan J.W. (1996) Re-Os ages of group IIA, IIIA, IVA, and IVB iron meteorites. Science 271, 1099-1102.

Tornabene H.A., Hilton C.D., Bermingham K.R., Ash R.D., Walker R.J. (2020) Genetics, age and crystallization history of group IIC iron meteorites. Geochim. Cosmochim. Acta 288, 3650.

Ulff-Møller F. (1998) Effects of liquid immiscibility on trace element fractionation in magmatic iron meteorites: A case study of group IIIAB. Meteorit. Planet. Sci. 33, 207-220.

Urey H.C. (1966) Chemical evidence relative to the origin of the solar system. Mon. Not. R. Astr. Soc. 131, 199-223.

Walker R.J., McDonough W.F., Honesto J., Chabot N.L., McCoy T.J., Ash R.D. and Bellucci J.J. (2008) Modeling fractional crystallization of group IVB iron meteorites. Geochim. Cosmochim. Acta 72, 2198-2216.

Wasson J.T. (1969) The chemical classification of iron meteorites-III. Hexahedrites and other irons with germanium concentrations between 80 and 200 ppm. Geochim. Cosmochim. Acta 33, 859-876.

Wasson J.T. and Sedwick S. (1969) Possible sources of meteoritic material from Hopewell Indian Burial Mounds. Nature 222, 22-24.

Wasson J.T. (1999) Trapped melt in IIIAB irons; solid/liquid elemental partitioning during the fractionation of the IIIAB magma. Geochim. Cosmochim. Acta 63, 2875-2889. 
Wasson J.T. and Choi B.-G. (2003) Main-group pallasites: chemical composition, relationship to IIIAB irons, and origin. Geochim. Cosmochim. Acta 67, 3079-3096.

Wasson J.T. (2016) Formation of the Treysa quintet and the main-group pallasites by impactgenerated processes in the IIIAB asteroid. Meteorit. Planet. Sci. 51, 773-784.

Wood J. A. (1978) Nature and evolution of the meteorite parent bodies: evidence from petrology and metallurgy. In NASA, Washington Asteroids (SEE N78-29007 19-91), pp. 45-55.A

Worsham E.A., Bermingham K.R., Walker R.J. (2016) Siderophile element systematics of IAB complex iron meteorites: new insights into the formation of an enigmatic group. Geochim. Cosmochim. Acta 188, 261-283.

Worsham E.A., Burkhardt C., Budde G., Fischer-Gödde M., Kruijer T.S., Kleine T. (2019) Distinct evolution of the carbonaceous and non-carbonaceous reservoirs: Insights from $\mathrm{Ru}, \mathrm{Mo}$, and W isotopes. Earth Planet. Sci. Lett. 521, 103-112.

Yang J., Goldstein J. I. and Scott E. R. D. (2010) Main-group pallasites: thermal history, relationship to IIIAB irons, and origin. Geochim. Cosmochim. Acta 74, 4471-4492. 
Table 1: Average siderophile element abundances of 6 IIF iron meteorites and 4 Eagle Station Pallasites (PES) determined by LA-

710 ICP-MS

\begin{tabular}{|c|c|c|c|c|c|c|c|c|c|c|c|}
\hline$I I F$ & Dorofeevka & Del Rio & Monahans (1938) & Purmela & Repeev Khutor & Corowa & PES & Itzawisis & Eagle Station & Karavannoe & Oued Bourdim 001 \\
\hline $\operatorname{Re}$ & $2.04 \pm 0.03$ & $1.60 \pm 0.07$ & $1.06 \pm 0.05$ & $0.74 \pm 0.05$ & $0.19 \pm 0.04$ & $0.06 \pm 0.01$ & & $1.7 \pm 0.2$ & $1.1 \pm 0.1$ & $0.80 \pm 0.06$ & $0.35 \pm 0.02$ \\
\hline Os & $27 \pm 1$ & $21 \pm 1$ & $11.5 \pm 0.2$ & $9.6 \pm 0.4$ & $1.33 \pm 0.08$ & $0.64 \pm 0.04$ & & $24 \pm 2$ & $15 \pm 1$ & $9.1 \pm 0.4$ & $3.5 \pm 0.2$ \\
\hline W & $1.26 \pm 0.07$ & $1.2 \pm 0.1$ & $2.6 \pm 0.5$ & $0.76 \pm 0.05$ & $0.72 \pm 0.04$ & $0.21 \pm 0.03$ & & $0.3 \pm 0.1$ & $0.19 \pm 0.05$ & $0.17 \pm 0.03$ & $0.33 \pm 0.05$ \\
\hline Ir & $23 \pm 1$ & $19.6 \pm 0.8$ & $13.8 \pm 0.2$ & $9.8 \pm 0.4$ & $2.8 \pm 0.2$ & $0.80 \pm 0.04$ & & $21 \pm 1$ & $11.6 \pm 0.8$ & $8.8 \pm 0.4$ & $5.7 \pm 0.1$ \\
\hline Mo & $11.4 \pm 0.6$ & $11.9 \pm 0.7$ & $13 \pm 2$ & $10.4 \pm 0.4$ & $13.1 \pm 0.9$ & $17 \pm 2$ & & $13 \pm 1$ & $12 \pm 2$ & $18 \pm 1$ & $14.4 \pm 0.7$ \\
\hline $\mathrm{Ru}$ & $21.7 \pm 0.7$ & $19.2 \pm 0.8$ & $18.6 \pm 0.4$ & $12.0 \pm 0.4$ & $11.0 \pm 0.3$ & $3.8 \pm 0.5$ & & $19 \pm 1$ & $18 \pm 1$ & $14 \pm 1$ & $11.3 \pm 0.8$ \\
\hline $\mathrm{Pt}$ & $27.3 \pm 0.7$ & $24 \pm 1$ & $25.4 \pm 0.4$ & $15.3 \pm 0.4$ & $16.1 \pm 0.5$ & $4.6 \pm 0.1$ & & $24 \pm 1$ & $21 \pm 2$ & $17.5 \pm 0.7$ & $17.0 \pm 0.5$ \\
\hline $\mathrm{Rh}$ & $2.55 \pm 0.09$ & $2.2 \pm 0.1$ & $2.34 \pm 0.08$ & $1.60 \pm 0.02$ & $2.12 \pm 0.05$ & $1.48 \pm 0.03$ & & $2.4 \pm 0.2$ & $2.2 . \pm 0.2$ & $2.0 \pm 0.1$ & $2.0 \pm 0.1$ \\
\hline $\mathrm{Ni}$ & $11.3 \pm 0.2$ & $11.6 \pm 0.5$ & $9.9 \pm 0.3$ & $11.1 \pm 0.3$ & $12.2 \pm 0.1$ & $13.2 \pm 0.6$ & & $15 \pm 2$ & $17 \pm 2$ & $19 \pm 2$ & $16 \pm 1$ \\
\hline Co & $6690 \pm 60$ & $6900 \pm 100$ & $6200 \pm 100$ & $6000 \pm 100$ & $7030 \pm 60$ & $6900 \pm 200$ & & $8400 \pm 600$ & $8000 \pm 1000$ & $8800 \pm 900$ & $9400 \pm 500$ \\
\hline $\mathrm{Fe}$ & $88.0 \pm 0.2$ & $87.7 \pm 0.5$ & $89.5 \pm 0.3$ & $88.3 \pm 0.3$ & $87.1 \pm 0.2$ & $86.1 \pm 0.6$ & & $84 \pm 2$ & $82 \pm 2$ & $80 \pm 2$ & $83.2 \pm 0.9$ \\
\hline $\mathrm{Pd}$ & $3.0 \pm 0.2$ & $2.7 \pm 0.1$ & $2.8 \pm 0.2$ & $2.6 \pm 0.2$ & $4.3 \pm 0.2$ & $5.0 \pm 0.1$ & & $4.2 \pm 0.7$ & $4.2 \pm 0.5$ & $5.1 \pm 0.6$ & $5.4 \pm 0.7$ \\
\hline As & $5.5 \pm 0.4$ & $4.9 \pm 0.1$ & $5.0 \pm 0.2$ & $5.1 \pm 0.1$ & $11.9 \pm 0.2$ & $17 \pm 1$ & & $11 \pm 2$ & $8 \pm 1$ & $10.9 \pm 0.6$ & $11.6 \pm 0.8$ \\
\hline $\mathrm{Au}$ & $0.80 \pm 0.04$ & $0.69 \pm 0.3$ & $0.69 \pm 0.05$ & $0.62 \pm 0.01$ & $1.4 \pm 0.1$ & $2.06 \pm 0.03$ & & $1.4 \pm 0.3$ & $1.1 \pm 0.1$ & $1.45 \pm 0.09$ & $1.6 \pm 0.1$ \\
\hline $\mathrm{Cu}$ & $320 \pm 20$ & $336 \pm 3$ & $240 \pm 10$ & $307 \pm 1$ & $293 \pm 7$ & $250 \pm 9$ & & $330 \pm 50$ & $290 \pm 30$ & $180 \pm 30$ & $230 \pm 10$ \\
\hline $\mathrm{Ga}$ & $10.0 \pm 0.5$ & $9.4 \pm 0.2$ & $9.3 \pm 0.6$ & $12.7 \pm 0.5$ & $10.4 \pm 0.2$ & $10.3 \pm 0.3$ & & $5.9 \pm 0.5$ & $4.7 \pm 0.4$ & $7.2 \pm 0.8$ & $7.8 \pm 0.2$ \\
\hline $\mathrm{Ge}$ & $132 \pm 4$ & $100 \pm 2$ & $123 \pm 2$ & $32 \pm 1$ & $159 \pm 3$ & $165 \pm 4$ & & $90 \pm 10$ & $68 \pm 5$ & $85 \pm 6$ & $118 \pm 2$ \\
\hline
\end{tabular}

711 Abundances are reported in ppm and wt. \% (Ni and Fe). 1SD uncertainties are also reported. 
Table 2: Highly siderophile element abundances and Re-Os isotope systematics of IIF iron meteorites and PES 713 determined by isotope dilution.

\begin{tabular}{|c|c|c|c|c|c|c|c|c|c|c|c|}
\hline Meteorite & Catalog & Mass & $\mathrm{Re}$ & Os & $\mathrm{Ir}$ & $\mathrm{Ru}$ & $\mathrm{Pt}$ & $\mathrm{Pd}$ & ${ }^{187} \mathrm{Re} /{ }^{188} \mathrm{Os}$ & ${ }^{187} \mathrm{Os} /{ }^{188} \mathrm{Os}$ & $\mathrm{E}_{\mathrm{Os}}$ \\
\hline \multicolumn{12}{|l|}{$I I F$} \\
\hline Dorofeevka & KMAN & 0.0735 & 2275 & 29818 & 24610 & 23750 & 27770 & 3494 & 0.3675 & 0.12444 & $+2 \pm 2$ \\
\hline Del Rio & USNM 6160 & 0.0415 & 1832 & 23474 & 20560 & 21490 & 25880 & 3282 & 0.3760 & 0.12505 & $+2 \pm 2$ \\
\hline Monahans (1938) & ASU 256 & 0.0630 & 1103 & 12037 & 14100 & 20770 & 25520 & 3231 & 0.4415 & 0.13119 & $+11 \pm 2$ \\
\hline rep & ASU 256 & 0.0824 & 1100 & 12007 & 14080 & 20760 & 25620 & 3226 & 0.4418 & 0.13118 & $+11 \pm 2$ \\
\hline Purmela & ASU 1515 & 0.0954 & 863.6 & 10988 & 10730 & 13850 & 17220 & 3484 & 0.3786 & 0.12519 & $+1 \pm 2$ \\
\hline Repeev Khutor & KMAN & 0.0405 & 186.4 & 1524.5 & 2867 & 11880 & 16860 & 4997 & 0.5901 & 0.14315 & $+13 \pm 2$ \\
\hline Corowa & USNM 7230 & 0.0751 & 75.69 & 795.62 & 868.2 & 3330 & 4931 & 6339 & 0.4585 & 0.13155 & $+1 \pm 2$ \\
\hline \multicolumn{12}{|l|}{ PES } \\
\hline Eagle Station & USNM & 0.0386 & 1167 & 15099 & 12310 & 17910 & 22240 & 4534 & 0.3723 & 0.12477 & $+2 \pm 2$ \\
\hline Karavannoe & MMGM & 0.0289 & 678.3 & 8879.5 & 8230 & 12910 & 16150 & 5832 & 0.3680 & 0.12584 & $+16 \pm 2$ \\
\hline rep & MMGM & 0.0456 & 687.6 & 8991.9 & 8310 & 12940 & 16170 & 5751 & 0.3684 & 0.12589 & $+16 \pm 2$ \\
\hline rep & MMGM & 0.0326 & 735.2 & 9362.5 & 8683 & 13660 & 17000 & 6248 & 0.3783 & 0.12586 & $+8 \pm 2$ \\
\hline Cold Bay & USNM & 0.0452 & 638.2 & 8413.1 & 7705 & 14310 & 20030 & 6497 & 0.3654 & 0.12656 & $+25 \pm 2$ \\
\hline Oued Bourdim 001 & ASU 1860 & 0.0643 & 369.7 & 3687.0 & 5819 & 12400 & 17060 & 6066 & 0.4836 & 0.13456 & $+12 \pm 2$ \\
\hline
\end{tabular}

714 Values are reported in grams for mass and ppb for HSE. EOs is the part per 10,000 deviation of the ${ }^{187} \mathrm{Os} /{ }^{188} \mathrm{Os}$ ratio

715 of a meteorite from a $4.568 \mathrm{Ga}$ reference isochron, calculated from an initial Solar System ${ }^{187} \mathrm{Os} /{ }^{188} \mathrm{Os}=0.09517$

716 and $\lambda=1.666 \times 10^{-11} \mathrm{yr}^{-1}$ (Smoliar et al., 1996; Archer et al., 2014). KMAN = Committee on Meteorites, Academy

717 of Sciences, Russia. MMGM = Maine Mineral and Gem Museum. USNM = Division of Meteorites, Department of

718 Mineral Sciences, Smithsonian Institution. ASU = Center for Meteorite Studies at Arizona State University. 
719 Table 3: Calculated parental melt compositions of the IIF irons

720 and PES.

\begin{tabular}{lllllllll}
\hline & $\mathrm{Re}$ & $\mathrm{Os}$ & $\mathrm{Ir}$ & $\mathrm{Ru}$ & $\mathrm{Pt}$ & $\mathrm{Pd}$ & $\mathrm{S}$ & $\mathrm{P}$ \\
\hline IIF M1 & 355 & 4200 & 4200 & 6800 & 8200 & 4250 & 13 & 0.4 \\
IIF M2 & 480 & 5800 & 5500 & 8500 & 10300 & 4300 & 11 & 0.5 \\
IIF M3 & 235 & 2750 & 2850 & 5100 & 6150 & 4200 & 15 & 0.4
\end{tabular}

$\begin{array}{lllllllll}\text { PES M1 } & 550 & 7000 & 6700 & 10000 & 12500 & 6800 & 6 & 0.7\end{array}$

721 Concentrations are in ppb for HSE and wt. \% for S and P. All

722 models use a $\mathrm{C}$ content of $<0.05 \mathrm{wt}$. \%. The IIF M2 and M3 define

723 the endmembers of the possible parental melt compositions with

724 relative abundances of HSE within the average \pm 2SD range

725 observed in carbonaceous chondrites. 


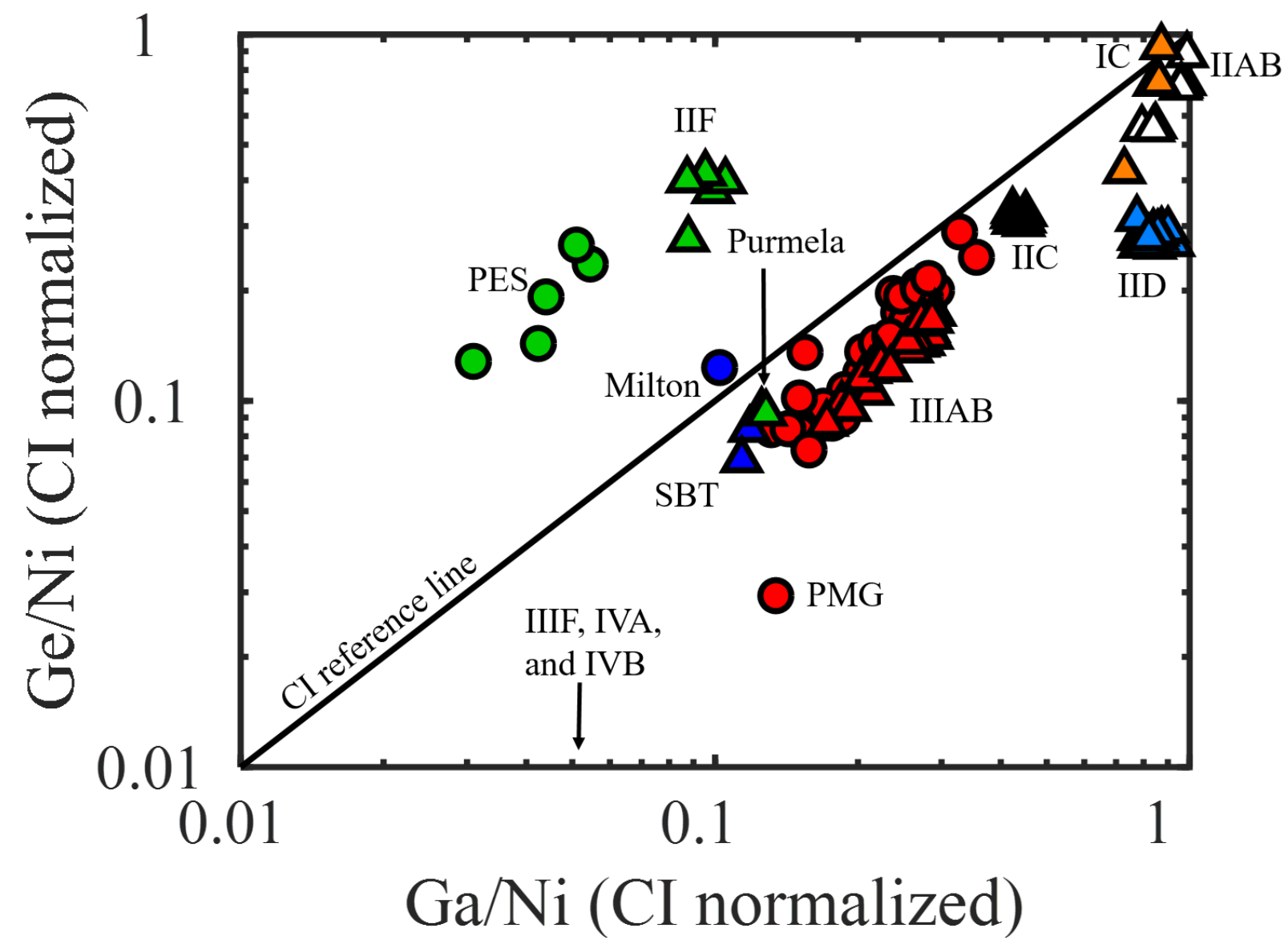

Fig. 1. Comparison of $\mathrm{Ga} / \mathrm{Ni}$ and $\mathrm{Ge} / \mathrm{Ni}$ values of the PES to magmatic iron meteorite groups. Data are compiled from this study and the literature. The PES are most similar to the IIF irons. The similarities between the PMG-IIIAB and Milton-SBT are also shown. Pallasites (PES = green, $\mathrm{PMG}=$ red, and Milton $=$ blue $)$ are shown as circles and iron meteorites $(\mathrm{IC}=$ orange, $\mathrm{IIAB}=$ white, $\mathrm{IIC}=$ black, $\mathrm{IID}=$ light blue, $\mathrm{IIF}=$ green, $\mathrm{IIIAB}=$ red, and SBT $=$ dark blue $)$ are shown as triangles. 

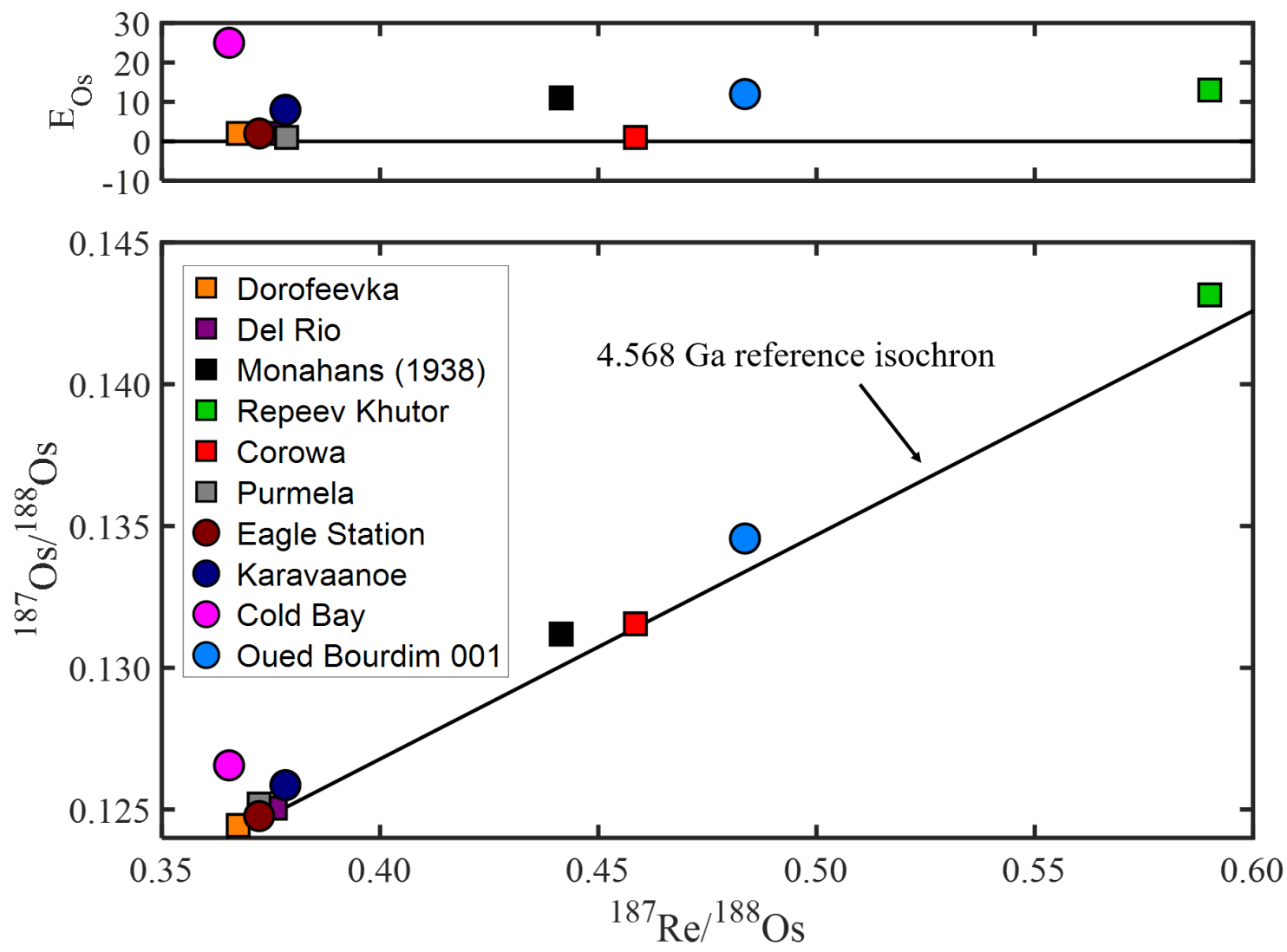

Fig. 2. (top) EOs vs. ${ }^{187} \mathrm{Re} /{ }^{188}$ Os plot for the iron meteorites and pallasites from this study. EOs is the parts per 10,000 deviation of the ${ }^{187} \mathrm{Os} /{ }^{188} \mathrm{Os}$ ratio of a sample from the $4.568 \mathrm{Ga}$ reference isochron in the bottom figure. (bottom) ${ }^{187} \mathrm{Os} /{ }^{188} \mathrm{Os} v s .{ }^{187} \mathrm{Re} /{ }^{188} \mathrm{Os}$ plotted with a $4.568 \mathrm{Ga}$ reference isochron, calculated from an initial Solar System ${ }^{187} \mathrm{Os} /{ }^{188} \mathrm{Os}=0.09517$ and $\lambda=1.666$ x $10^{-11} \mathrm{yr}^{-1}$ (Smoliar et al., 1996; Archer et al., 2014). Uncertainties are smaller than the symbol size. 

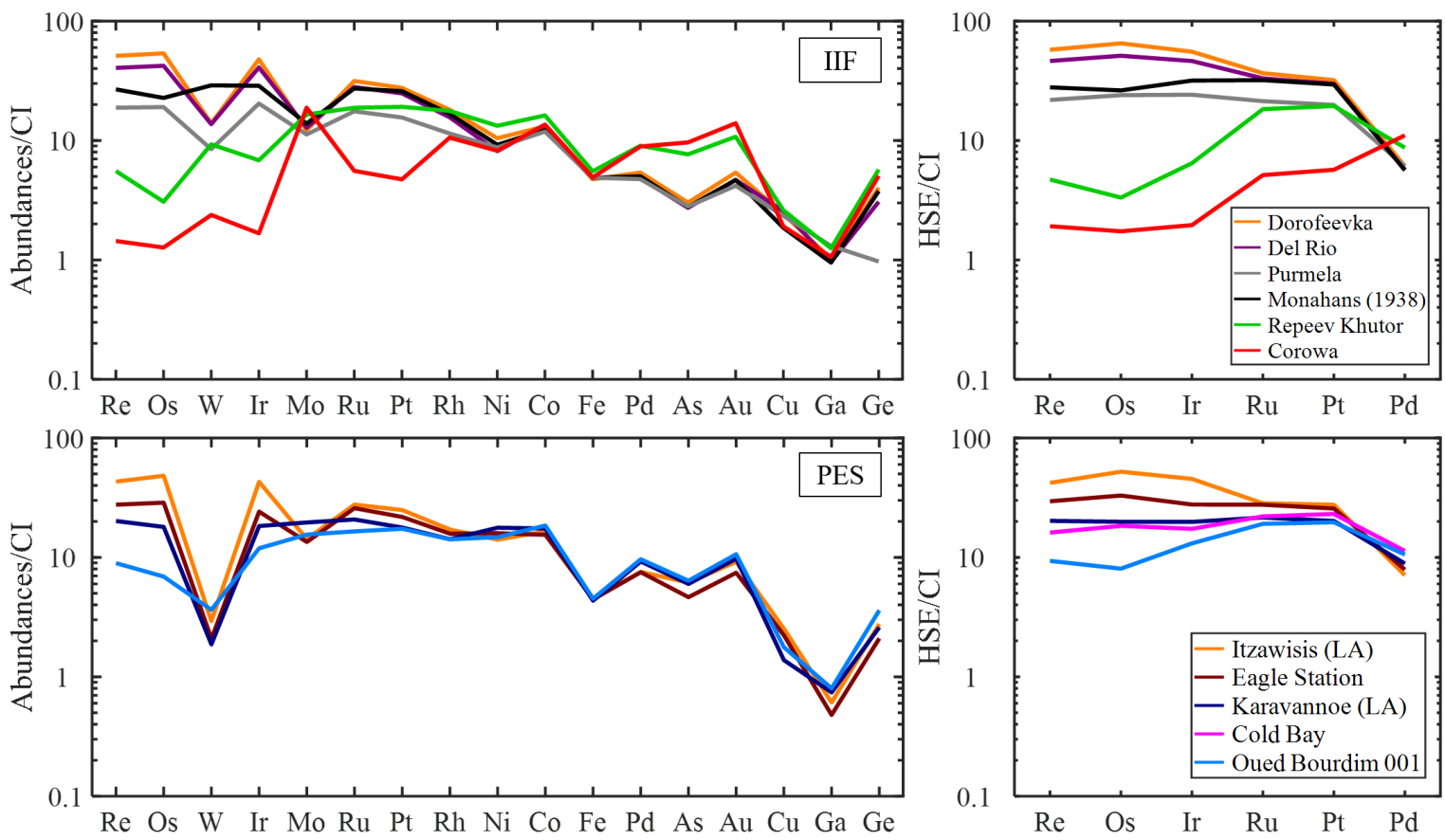

Fig. 3. (left) Siderophile element abundances, normalized to CI chondrites (Lodders, 2003), for 6 IIF irons and metal from 4 PES obtained by LA-ICP-MS. (right) Highly siderophile element abundances, normalized to CI chondrites (Horan et al., 2003), for the IIF irons and PES. Data were obtained by isotope dilution except for Itzawisis and Karavannoe, which were obtained by LA-ICP-MS. 

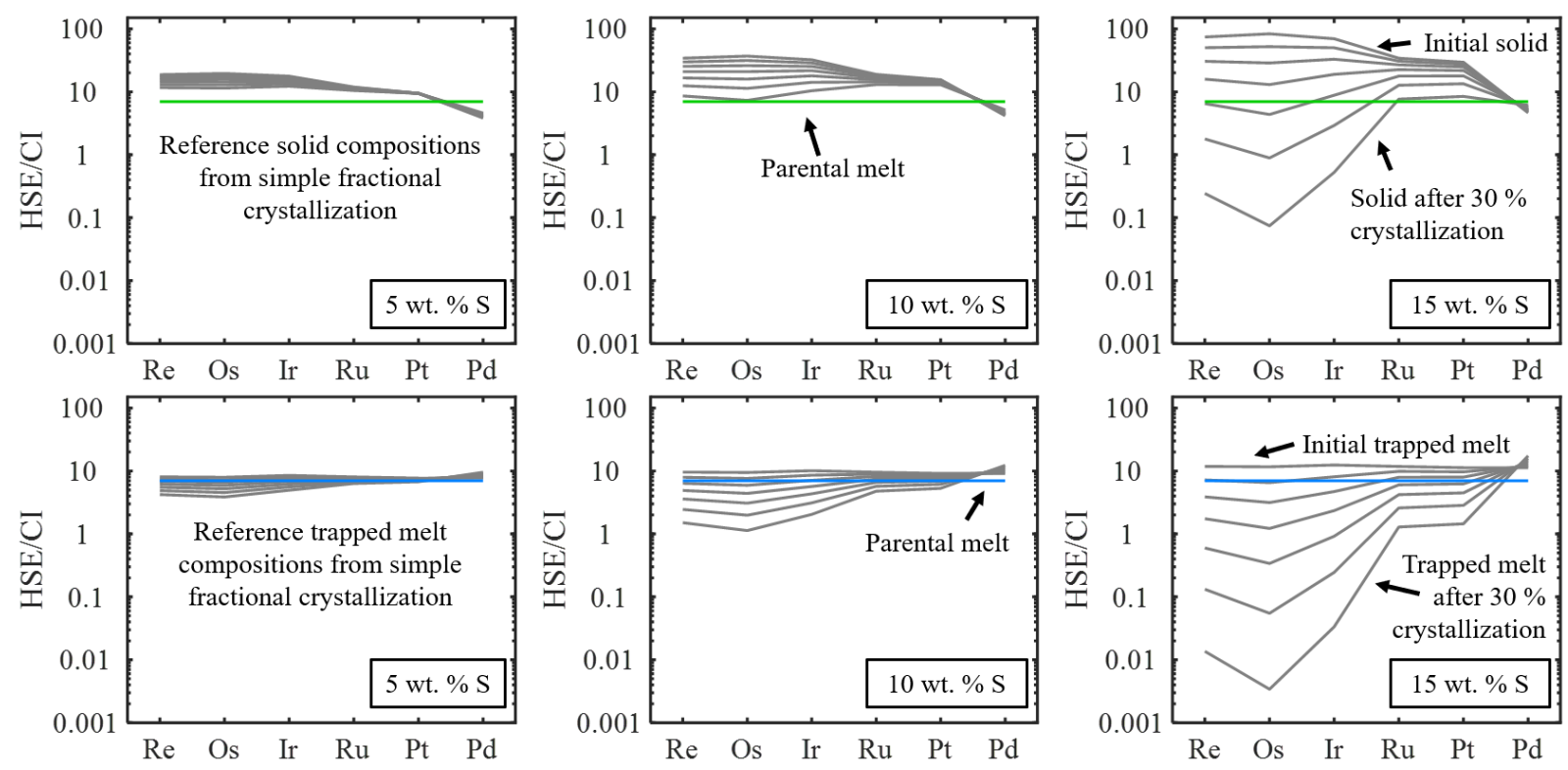

Fig. 4. Model HSE abundances, normalized to CI-chondrites (Horan et al., 2003), of equilibrium solids and trapped melt produced at $5 \%$ intervals between initial and $30 \%$ fractional crystallization for 3 different $\mathrm{S}$ parental melt contents. The D values for the HSE are determined from the parameterization method discussed by Chabot et al. (2017). 

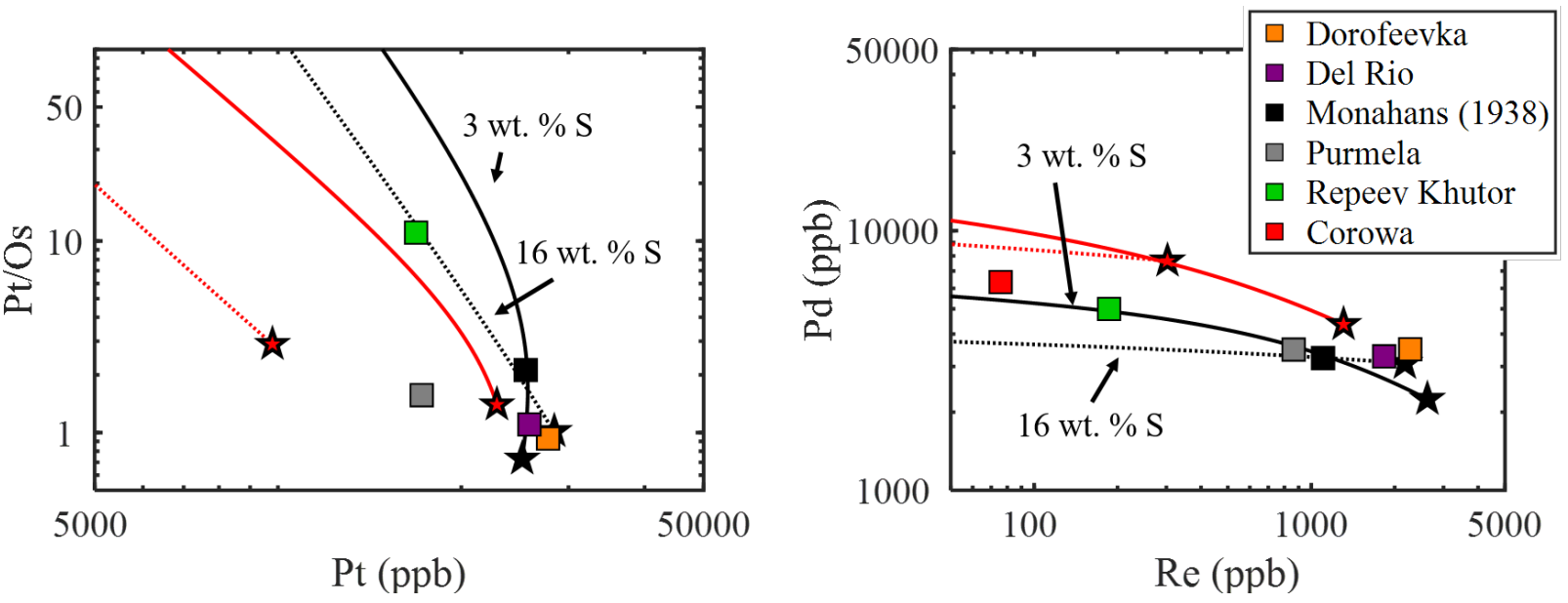

752 Fig. 5. Fractional crystallization models compared to the IIF irons. The Pt/Os $v s$. Pt compositions and Pd vs. Re compositions of any 2 IIF irons cannot be accounted for as equilibrium solids from the same metal system. Solid metal and liquid metal evolution lines are shown in black and red, respectively. Initial solid and liquid compositions are shown as black and red stars, respectively. 

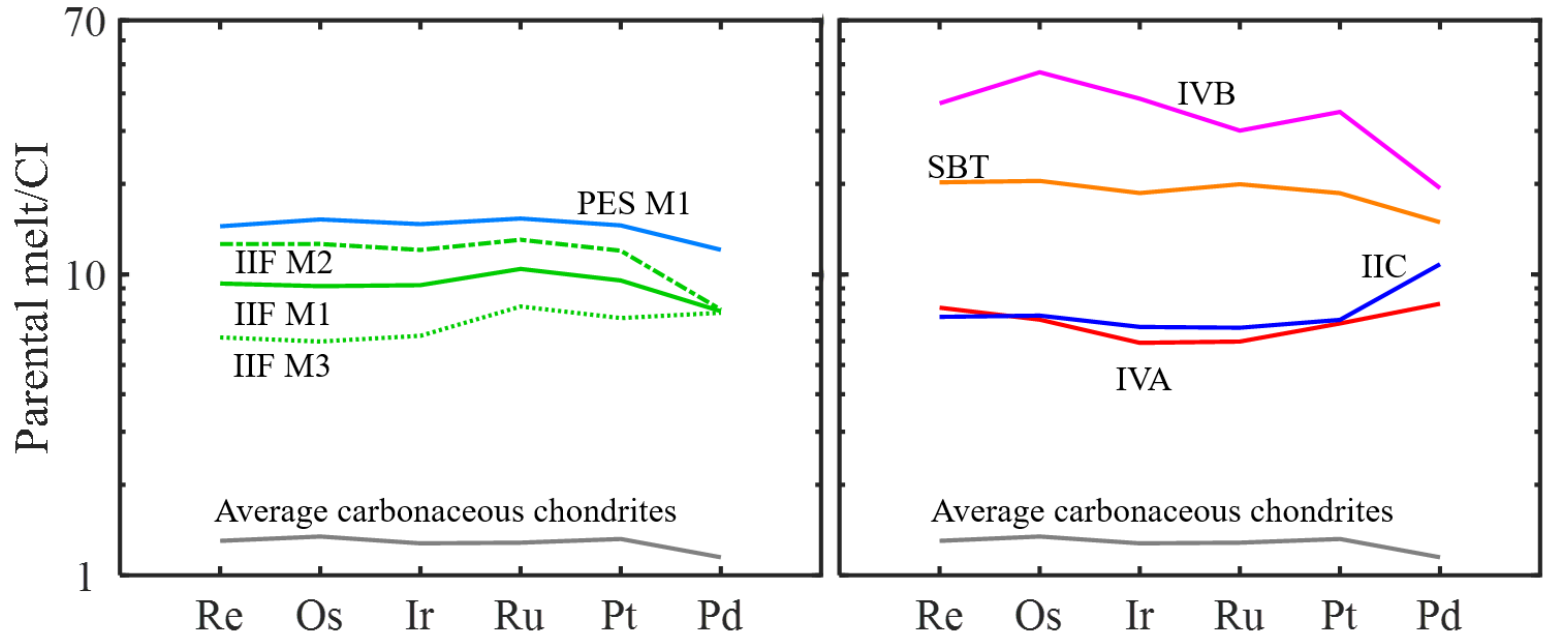

756

757

758

759

760

761

Fig. 6. Calculated HSE parental melt compositions, normalized to CI chondrites (Horan et al., 2003), of the IIF M1, M2, and M3 as well as the PES M1 compared to parental melt compositions of the IVB (Walker et al., 2008), IVA (McCoy et al., 2011), SBT (Hilton et al., 2019), and IIC iron meteorites (Tornabene et al., 2020). The average HSE composition of carbonaceous chondrites is also shown (Horan et al., 2003; Fischer-Gödde et al., 2010). 

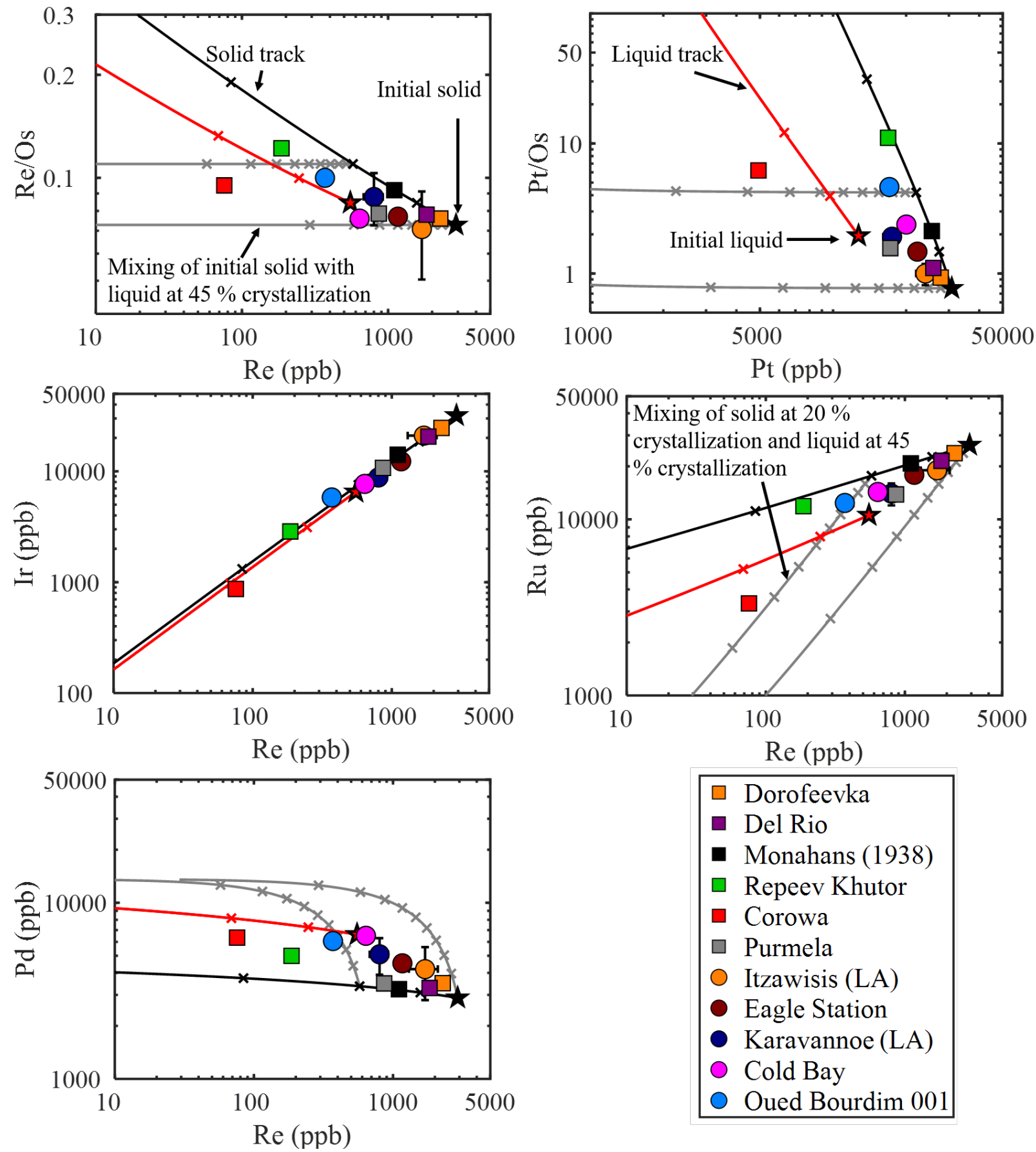

\begin{tabular}{|ll|}
\hline$\square$ Dorofeevka \\
$\square$ Del Rio \\
$\square$ Monahans (1938) \\
$\square$ Repeev Khutor \\
$\square$ Corowa \\
$\square$ Purmela \\
$\bigcirc$ Itzawisis (LA) \\
Eagle Station \\
- Karavannoe (LA) \\
0 Cold Bay \\
0 Oued Bourdim 001 \\
\hline
\end{tabular}

Fig. 7. Fractional crystallization model of IIF M1. This model can account for the HSE compositions of the IIF irons and PES through various degrees of solid metal-liquid metal mixing. Solid metal and liquid metal evolution lines are shown in black and red, respectively. Initial solid and liquid compositions are shown as black and red stars, respectively. Grey lines reflect mixing of solid at initial, $10 \%$, and $20 \%$ fractional crystallization with a liquid after $45 \%$ crystallization. Tick marks on solid and liquid evolution curves as well as solid metal-liquid metal mixing lines reflect $10 \%$ increments. 


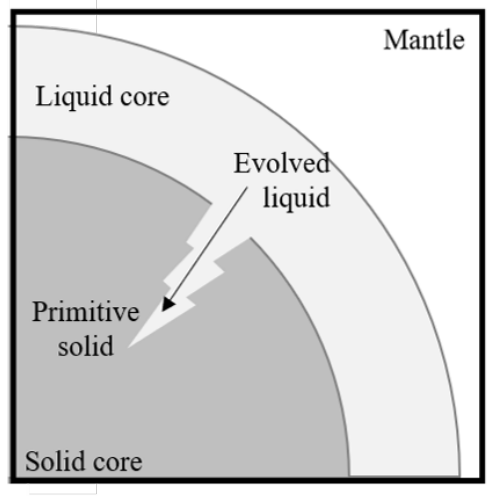

Non-equilibrium mixing

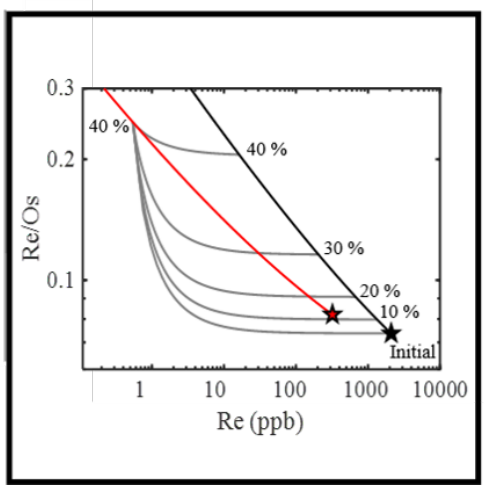

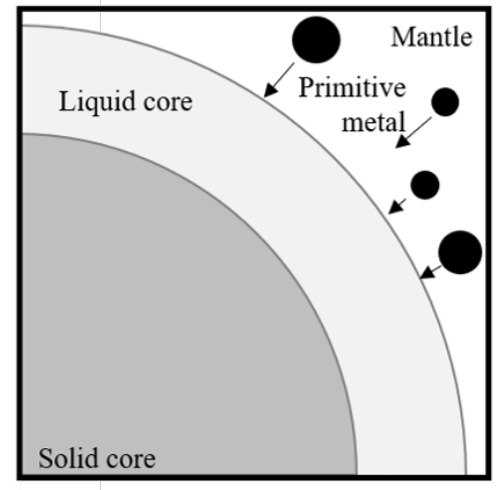

Late segregation

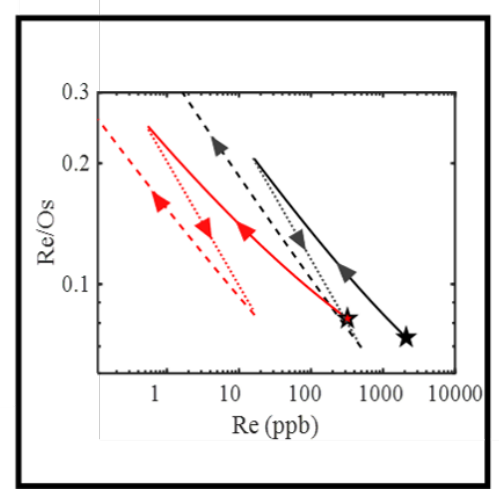

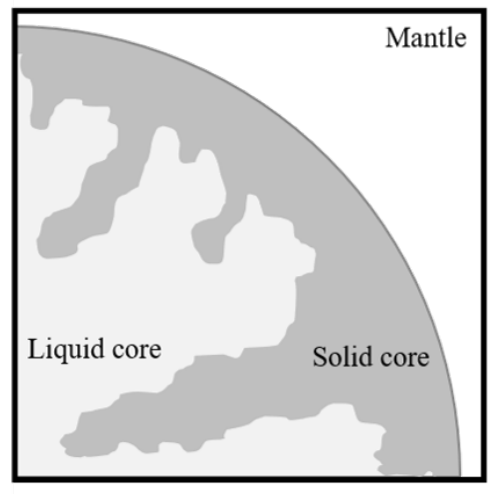

Dendritic crystallization

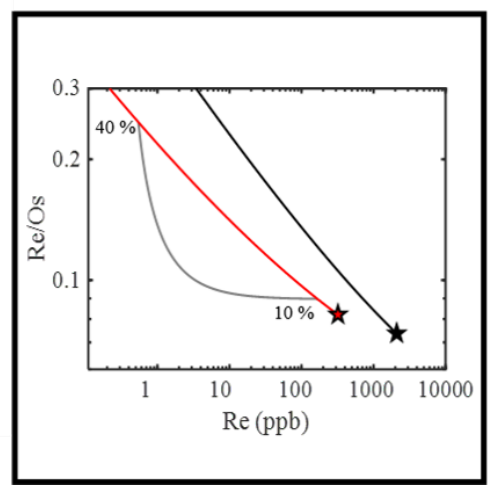

Fig. 8. Cartoons depicting possible pathways, including non-equilibrium solid metal-liquid metal mixing, late segregation of primitive, liquid metal from the mantle to an evolved, liquid outer core, and dendritic crystallization, for forming the IIF iron meteorites. Effects of these mechanisms on the Re-Os systematics of liquid metal and crystallizing metal are also shown. 

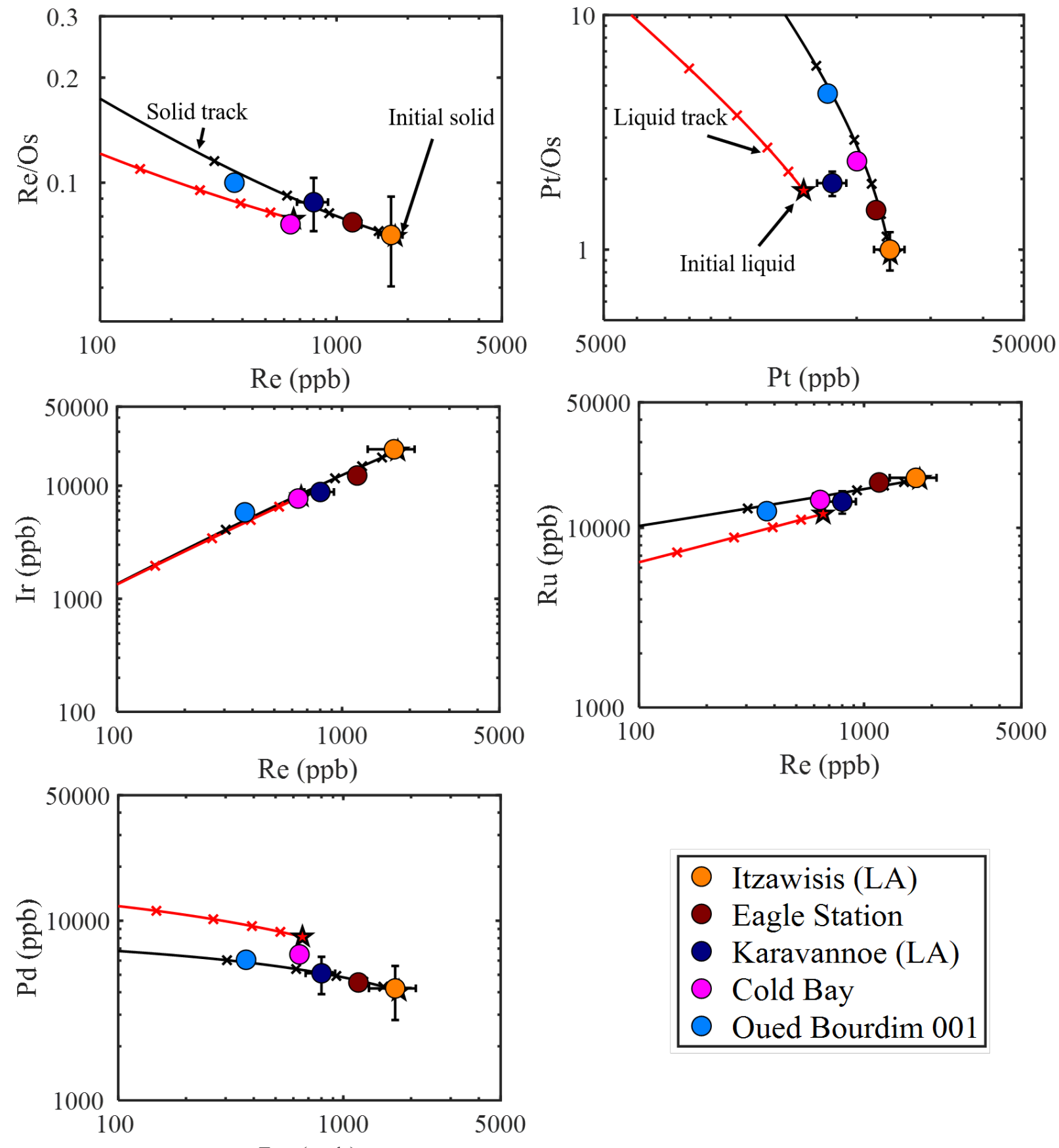

\begin{tabular}{|ll|}
\hline & Itzawisis (LA) \\
- & Eagle Station \\
Karavannoe (LA) \\
Cold Bay \\
Oued Bourdim 001 \\
\hline
\end{tabular}

Fig. 9. Fractional crystallization PES M1, which can account for most of the HSE compositions of the PES as equilibrium solids. Solid metal and liquid metal evolution lines are shown in black and red, respectively. Initial solid and liquid compositions are shown as black and red stars, respectively. Tick marks on solid and liquid evolution curves reflect $10 \%$ increments. 


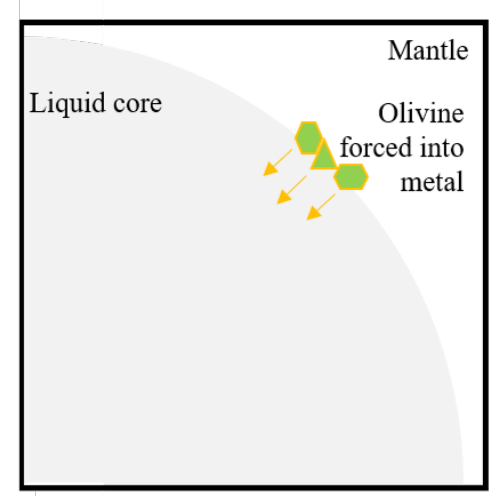

1. Metal is liquid, olivine is forced into metal

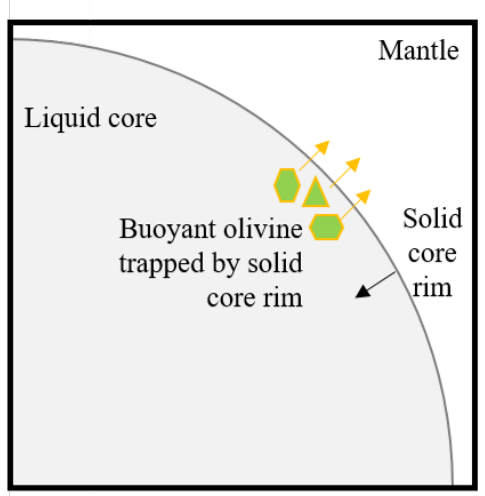

2. Outer core crystallizes, traps olivine in liquid core

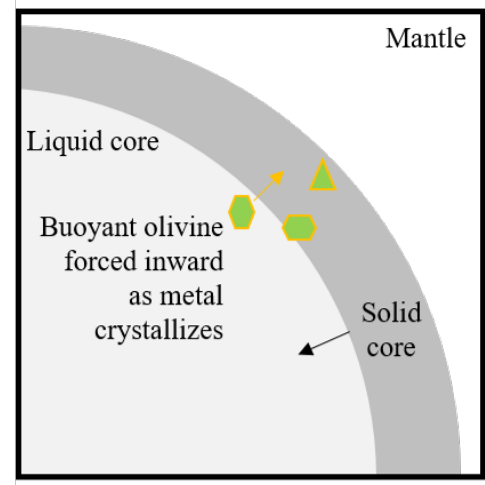

3. Inward crystallization pushes olivine inward, while some olivine is trapped during crystallization

Fig. 10. Cartoon depicting the proposed formation sequence of the PES. Olivine at the core-mantle boundary is forced into a liquid core by impact and the liquid core then quickly crystallizes an outer rim, trapping the buoyant olivine in the core. As the core crystallizes inward, some olivine is trapped in the crystallizing metal while the remaining olivine is pushed further inward by the crystallizing metal front. 


\title{
Crystallization histories of the group IIF iron meteorites and Eagle Station pallasites
}

\author{
C.D. Hilton*, R.D. Ash, and R.J. Walker
}

Department of Geology, University of Maryland, College Park, Maryland, 20742, USA (chilton@terpmail.umd.edu)

\section{Supplemental Information}

\section{S1. Fractional Crystallization Modeling}

The concentrations of $\mathrm{S}, \mathrm{P}, \mathrm{C}$, and HSE in liquid during fractional crystallization were determined using Eq. $\mathrm{S} 1$. In this equation, $\mathrm{F}_{\mathrm{n}}$ is the fraction of liquid ( $\mathrm{n}=100$ is pure liquid), $\mathrm{C}_{\mathrm{Ln}}$ is the concentration of an element in the liquid phase at $F_{n}$, and $D_{n}$ is the partition coefficient of an element. The concentrations of these elements were calculated at each $0.1 \%$ of crystallization. A constant partition coefficient of 0.001 was used for S (Walker et al., 2008). The partition coefficients for $\mathrm{P}$ and $\mathrm{C}$ were determined at each $\mathrm{F}_{\mathrm{n}}$ by considering the concentration of $\mathrm{S}$ and $\mathrm{P}$ or $\mathrm{S}$ and $\mathrm{C}$, respectively, in the liquid at $\mathrm{F}_{\mathrm{n}+1}$. Equation $\mathrm{S} 2$ is used to account for the effects of $\mathrm{S}$ on P and C partitioning behavior (Chabot and Jones, 2003).

Values of $D_{o}$ for $P$ and $C$ are taken from Chabot et al. (2017) and Worsham et al. (2016), respectively. The $\beta_{\mathrm{SPC}}$ variable is determined using Eq. S3 (Jones and Malvin, 1990), in which $\beta_{\mathrm{S}}$ and $\beta_{\mathrm{P}}$ are taken from Chabot et al. (2017) and $\beta_{\mathrm{C}}$ is taken from Worsham et al. (2016). For P, the effects of $\mathrm{C}$ are not considered and for $\mathrm{C}$, the effects of $\mathrm{P}$ are not considered. The $\beta_{\mathrm{SPC}}$ and "Fe domains" (Eq. S4; Chabot et al., 2017) variables are calculated at each $F_{n}$, where $X_{\mathrm{i}}$ is the mole fraction of an element. Initial S, P, and C contents were determined iteratively. 
After determining the concentration of $\mathrm{S}, \mathrm{P}$, and $\mathrm{C}$ at each $\mathrm{F}_{\mathrm{n}}$, the $\mathrm{D}$ values for the $\mathrm{HSE}$ are calculated at each $\mathrm{F}_{\mathrm{n}}$ using Eq. S2-S4 by collectively considering the changes in $\mathrm{S}, \mathrm{P}$, and $\mathrm{C}$ content

811

812

813

814 in the liquid (Jones and Malvin, 1990; Chabot and Jones, 2003; Worsham et al., 2016; Chabot et al., 2017). Values for $D_{0}, \beta_{s}, \beta_{P}$, and $\beta_{C}$ for the HSE are allowed to vary within the $2 \sigma$ uncertainties provided by Chabot et al (2017) in order to achieve the best model fit. The concentrations of HSE in the liquid at each $\mathrm{F}_{\mathrm{n}}$ are then determined using Eq. S1 and the solid composition $\left(\mathrm{C}_{\mathrm{Sn}}\right)$ at each $\mathrm{F}_{\mathrm{n}}$ is determined using Eq. S5. For solid metal-liquid metal mixing, the composition of the liquid endmember ("trapped melt") was determined from $\mathrm{C}_{\mathrm{Ln}}$ following the approach of Chabot (2019). The concentration of $\mathrm{S}$ in the liquid at each $\mathrm{F}_{\mathrm{n}}$ was divided by 36.5 to determine the " $\mathrm{x}$ " value. The HSE concentrations of the trapped melt were determined by Eq. S6. Best fit initial HSE contents were determined iteratively, along with $\mathrm{S}, \mathrm{P}$, and $\mathrm{C}$.

$$
\begin{gathered}
\text { Eq. S1: } C_{L n-1}=\frac{C_{L n}}{\left(F_{n-1}+1-F_{n-1} D_{n-1}\right)} \\
\text { Eq. S2: } \frac{1}{D}=\frac{[\text { Fe domains }]^{\beta_{S P C}}}{D_{0}} \\
\text { Eq. S3: } \beta_{S P C}=\left[\frac{2 X_{S}}{2 X_{S}+4 X_{P}+4 X_{C}}\right] \beta_{S}+\left[\frac{4 X_{P}}{2 X_{S}+4 X_{P}+4 X_{C}}\right] \beta_{P}+\left[\frac{4 X_{C}}{2 X_{S}+4 X_{P}+4 X_{C}}\right] \beta_{C} \\
\text { Eq. S4: Fe domains }=\frac{1-2 X_{S}-4 X_{P}-4 X_{C}}{1-X_{S}-3 X_{P}-3 X_{C}} \\
\text { Eq. S5: } C_{S n}=C_{L n} D_{n} \\
\text { Eq. S6: } C_{\text {trapped melt }}=\frac{C_{L n}}{(1-x)}
\end{gathered}
$$


829 Buchwald V. F. (1975) Handbook of Iron Meteorites. University of California Press.

830

831

832

833

834

835

836

837

838

839

840

841

842

843

844

845

846

847

848

849

850

851

Chabot N. L. and Jones J. H. (2003) Parameterizing iron meteorite partitioning experiments. Meteorit. Planet. Sci. 37, 1425-1436.

Chabot N.L., Wollack E.A., McDonough W.F., Ash R.D., Saslow S.A. (2017) Experimental determination of partitioning in the Fe-Ni system for applications to modeling meteoritic metals. Meteorit. Planet. Sci. 52, 1133-1145.

Chabot N.L. (2019) Revised trapped melt model for iron meteorites. $82^{\text {nd }}$ Annual Meeting of The Meteoritical Society, 6025 (abst).

Jones J. H. and Malvin D. J. (1990) A nonmetal interaction model for the segregation of the trace metals during solidification of $\mathrm{Fe}-\mathrm{Ni}-\mathrm{S}, \mathrm{Fe}-\mathrm{Ni}-\mathrm{P}, \mathrm{Fe}-\mathrm{Ni}-\mathrm{S}-\mathrm{P}$ alloys. Metall. Trans. B 21B, 697-706.

Walker R.J., McDonough W.F., Honesto J., Chabot N.L., McCoy T.J., Ash R.D. and Bellucci J.J. (2008) Modeling fractional crystallization of group IVB iron meteorites. Geochim. Cosmochim. Acta 72, 2198-2216.

Worsham E.A., Bermingham K.R., Walker R.J. (2016) Siderophile element systematics of IAB complex iron meteorites: new insights into the formation of an enigmatic group. Geochim. Cosmochim. Acta 188, 261-283. 